\title{
Sensitivities and Responses of Land Surface Temperature to Deforestation-Induced Biophysical Changes in Two Global Earth System Models ${ }^{\mathfrak{D}}$
}

\author{
WEILIN LiAO AND XIAOPING LIU \\ Guangdong Key Laboratory for Urbanization and Geo-simulation, School of Geography and Planning, \\ Sun Yat-sen University, Guangzhou, China \\ ELIZABETH BURAKOWSKI \\ Institute for the Study of Earth, Oceans, and Space, University of New Hampshire, Durham, New Hampshire
}

DAGANG WANG

School of Geography and Planning, Sun Yat-sen University, Guangzhou, China

LINYING WANG AND DAN LI

Department of Earth and Environment, Boston University, Boston, Massachusetts

(Manuscript received 26 September 2019, in final form 27 May 2020)

\begin{abstract}
While the significance of quantifying the biophysical effects of deforestation is rarely disputed, the sensitivities of land surface temperature (LST) to deforestation-induced changes in different biophysical factors (e.g., albedo, aerodynamic resistance, and surface resistance) and the relative importance of those biophysical changes remain elusive. Based on the subgrid-scale outputs from two global Earth system models (ESMs, i.e., the Geophysical Fluid Dynamics Laboratory Earth System Model and the Community Earth System Model) and an improved attribution framework, the sensitivities and responses of LST to deforestation are examined. Both models show that changes in aerodynamic resistance are the most important factor responsible for LST changes, with other factors such as albedo and surface resistance playing secondary but important roles. However, the magnitude of the contributions from different biophysical factors to LST changes is quite different for the two ESMs. We find that the differences between the two models in terms of the sensitivities are smaller than those of the corresponding biophysical changes, indicating that the dissimilarity between the two models in terms of LST responses to deforestation is more related to the magnitude of biophysical changes. It is the first time that the attribution of subgrid surface temperature variability is comprehensively compared based on simulations with two commonly used global ESMs. This study yields new insights into the similarity and dissimilarity in terms of how the biophysical processes are represented in different ESMs and further improves our understanding of how deforestation impacts on the local surface climate.
\end{abstract}

\section{Introduction}

Land-use/land-cover change (LULCC) such as deforestation has long been recognized as an important anthropogenic forcing to influence local, regional, and global climate (Mahmood et al. 2014; Pielke et al. 2011;

Supplemental information related to this paper is available at the Journals Online website: https://doi.org/10.1175/JCLI-D-190725.s1.

Corresponding author: Xiaoping Liu, liuxp3@mail.sysu.edu.cn
Bonan 2008; Findell et al. 2007; Feddema et al. 2005; Brovkin et al. 2004). Deforestation can lead to changes in the terrestrial carbon storage and thus the atmospheric $\mathrm{CO}_{2}$ concentration, thereby affecting the warming of global climate (biogeochemical effect) (Arora and Boer 2010; Shevliakova et al. 2013). In addition, deforestation modifies land surface properties and states such as albedo, aerodynamic resistance (mainly controlled by the surface roughness), and surface resistance (mainly controlled by soil moisture and vegetation characteristics) (Pielke et al. 2011), and thus alters the surface fluxes of water, energy, and momentum (Bonan 2008; Bright et al. 2015) and the 
surface and near-surface climate (biophysical effect), which is the focus of this study. The biophysical effect can amplify or dampen the local surface temperature response to the increasing greenhouse gas emissions (Bonan 2008; Schultz et al. 2016; Zeng et al. 2017). As a result, quantifying the biophysical effect is important for understanding the local impact of deforestation and also for informing land-based mitigation strategies that aim to reduce the surface temperature.

Global Earth system models (ESMs) are useful tools for diagnosing deforestation impacts. Many previous studies used the difference between two experiments forced by different land-cover scenarios to represent the impact of deforestation (e.g., one experiment using potential vegetation or preindustrial land-cover scenario and another experiment using historical LULCC or current land-cover scenario) (Findell et al. 2007; Chen and Dirmeyer 2016; de Noblet-Ducoudré et al. 2012; Lawrence and Chase 2010). These modeling studies have found a latitudinal dependence of deforestationinduced surface temperature changes (Lawrence and Chase 2010; Luyssaert et al. 2014; Li et al. 2015, 2016; Schultz et al. 2017; Malyshev et al. 2015), which is consistent with observational studies. Such a result is often believed to be caused by the opposite surface temperature responses to the decrease in evapotranspiration and the increase in albedo associated with deforestation, with the former (a warming effect) dominating in the tropics while the latter (a cooling effect) dominating in the boreal regions (Bonan 2016; Davin and de NobletDucoudré 2010). However, their relative importance, which determines whether deforestation has a net cooling or warming effect, remains elusive in the temperate midlatitudes. Therefore, it is still important to find an effective way to quantify the relative importance of different biophysical changes associated with deforestation.

In fact, the differences between the two experiments include both local and nonlocal effects of LULCC and can be affected by model internal variability (Malyshev et al. 2015; Pitman et al. 2009). If one were to compare the two experiments, the atmospheric conditions at the bottom of the atmospheric model (which is typically $\sim 50 \mathrm{~m}$ ) would be different between these two experiments (even with the same model), which can further contribute to the differences in the surface temperature between croplands and forests (these effects are sometimes called atmospheric feedbacks) (Chen and Dirmeyer 2020). Nowadays, most ESMs represent surface heterogeneity in terms of land-use/land-cover types as subgrid tiles (Boysen et al. 2014; Dunne et al. 2012, 2013; Oleson et al. 2013). Such a tiling (also sometimes called mosaic) approach has been used by the climate modeling community for nearly 30 years now (Lawrence et al. 2016). In the tiling approach, different subgrid tiles experience the same atmospheric conditions at the bottom of the atmospheric model but produce different land surface temperatures (LSTs) (as well as near-surface air temperatures) due to their unique biophysical and biogeochemical processes. The subgrid LST variability can thus be useful for studying the impact of deforestation on the local surface climate with only one experiment. However, it should be pointed out that in doing so there are no differences in the atmospheric conditions at the bottom of the atmospheric model between different subgrid tiles (e.g., forests and croplands) and thus essentially only the local effects of LULCC are studied.

Different ESMs have very different strategies to represent subgrid surface variability, different physical parameterizations, and even different standard output variables (Lawrence et al. 2016). How the local LST response to deforestation simulated by different ESMs can be compared remains an important but unanswered question. The overarching goal of this paper is to compare the sensitivities and responses of LST to deforestation based on the subgrid-scale outputs from global ESMs using an improved attribution framework. This is timely given that the ongoing Land Use Model Intercomparison Project (LUMIP), which is part of the Coupled Model Intercomparison Project, phase 6 (CMIP6), will provide subgrid-scale information (Lawrence et al. 2016). It can be foreseen that in future intercomparison projects, subgridscale information will only become increasingly available. As a starting point, we use two global ESMs, the Geophysical Fluid Dynamics Laboratory (GFDL) Earth System Model (ESM2Mb) and the Community Earth System Model (CESM 1.3), and focus on the difference between forests and croplands, which is viewed as a representation of the local effect of deforestation. However, the attribution framework is expected to be broadly applicable to other ESMs and LULCC scenarios.

The paper is organized as follows: section 2 describes the model simulations, and section 3 presents the attribution framework; section 4 presents the results, and section 5 concludes the study.

\section{Model simulations}

As mentioned before, in this study two global ESMs (i.e., the GFDL-ESM2Mb model and the CESM 1.3 model) are used. Land surface heterogeneity in these two models is represented by a tiling structure (with hierarchy), which enables comparisons between different land-use/land-cover categories within each grid cell (Shevliakova et al. 2009; Milly et al. 2014; Oleson et al. 2013). However, the strategy of land-use 
tile-reporting/aggregation is different for the two models, as discussed in Lawrence et al. (2016).

Within each grid cell, the land surface model component (LM3) of the GFDL-ESM2Mb represents four major vegetation types beyond glaciers and lakes, including natural or undisturbed vegetation (which can be either forest or grassland), pasture, cropland, and secondary vegetation (Shevliakova et al. 2009; Dunne et al. 2012, 2013; Milly et al. 2014). The tiling structure of LM3 is designed to accommodate the LULCC data provided by Hurtt et al. (2011). Each tile has its own energy and water balances throughout the vegetation-soil column and its own exchange coefficients with the atmosphere, but the atmosphere only receives the area-averaged fluxes of the grid cell. The simulations used in this study are similar to the historical simulations by GFDL-ESM2Mb in phase 5 of the Coupled Model Intercomparison Project (CMIP5) and have been described in Malyshev et al. (2015). Subgridlevel outputs in the period of 1980-2005 at monthly and $2^{\circ}$ latitude $\times 2.5^{\circ}$ longitude resolutions are analyzed in this study.

The CESM model used in this study is the coupled Community Atmosphere Model, version 5.3 (Neale et al. 2010) and Community Land Model (CLM), version 4.5 (Oleson et al. 2013). CLM resolves the subgrid land heterogeneity using three hierarchies, that is, land units, columns, and plant function types (PFTs). Each grid cell can include up to five different land units (i.e., vegetated, crop, lake, glacier, and urban). Each land unit can include multiple columns, and each column can include multiple PFTs. For example, up to 15 PFTs can be assigned to a soil column and then to a vegetated land unit. Their fluxes are computed at the PFT level, and then area-weighted averaged to the column level and then to the land unit level. The CESM simulation used here is conducted from 1979 to 2008 with a 50-yr spinup period following Atmospheric Intercomparison Project protocols (Burakowski et al. 2018). We use the subgrid PFTlevel outputs in the period of 1980-2005 at monthly and $1^{\circ}$ resolutions.

Given the difference in the spatial resolutions of the two models, we use a grid resolution of $2^{\circ}$ latitude $\times 2.5^{\circ}$ longitude for a consistent comparison. Hence, the results from the CESM model are interpolated to the grid used by the GFDL-ESM2Mb model based on the triangulationbased natural neighbor method.

We compare two land-cover types (i.e., forests and croplands), whose information can be obtained or aggregated from subgrid tiles of PFTs. In the GFDLESM2Mb model, the natural vegetation tile that is also forest and the cropland tile are used. In the CESM model, the information in the forest tile (such as surface fluxes) is the area-weighted average over all types of trees (i.e., broadleaf deciduous tree, broadleaf evergreen tree, needleleaf deciduous tree, and needleleaf evergreen tree) at the PFT level, while the cropland information is also the area-weighted average over all unmanaged rainfed crops at the PFT level. Figures 1 and 2 show the fractions of forests and croplands averaged over 1980-2005 in the two models, respectively. The spatial patterns of forest fraction in the two models are quite different, especially near the northern high latitudes. In the GFDL-ESM2Mb model, the fraction of forests is larger over the Amazon, Indonesia, and the North Pole but smaller over eastern America; in the CESM model, it is larger over eastern North America, around the latitude of $60^{\circ} \mathrm{N}$, and in the tropics, but smaller over the North Pole. These differences can be traced to how forests are represented in the two models. Compared to forests, the spatial patterns of cropland fraction in the two models are similar. The fraction of croplands is large over eastern America, Europe, India, and eastern China.

\section{The attribution framework}

In this study, we employ a recently proposed tworesistance mechanism (TRM) attribution method (Li et al. 2019; Liao et al. 2018; Rigden and Li 2017) and further improve it. The attribution method starts from the surface energy balance equation:

$$
R_{\text {net }}=S_{\text {in }}(1-\alpha)+\varepsilon L_{\text {in }}-\varepsilon \sigma T_{s}^{4}=H+L E+G,
$$

where $S_{\text {in }}$ is the incoming shortwave radiation, $\alpha$ is the surface albedo, $L_{\text {in }}$ is the incoming longwave radiation, $\varepsilon$ is the surface emissivity, $\sigma$ is the Stephan-Boltzmann constant, and $T_{s}$ is the LST. Based on the aerodynamic resistance concept, the sensible heat flux is parameterized as follows (Monteith and Unsworth 2013):

$$
H=\frac{\rho c_{p}}{r_{a}}\left(T_{s}-T_{a}\right)
$$

where $\rho$ is the air density, $c_{p}$ is the specific heat of air at constant pressure, $r_{a}$ is the aerodynamic resistance, and $T_{a}$ is the air temperature.

The latent heat flux is parameterized using the surface resistance concept (Monteith and Unsworth 2013), as follows:

$$
L E=\frac{\rho L_{v}}{r_{a}+r_{s}}\left[q_{s}^{*}\left(T_{s}\right)-q_{a}\right],
$$

where $L_{v}$ is the latent heat of vaporization, $r_{s}$ is the surface resistance, $q_{s}^{*}$ is the saturated specific humidity at $T_{s}$, and $q_{a}$ is the atmosphere specific humidity. As a result, 

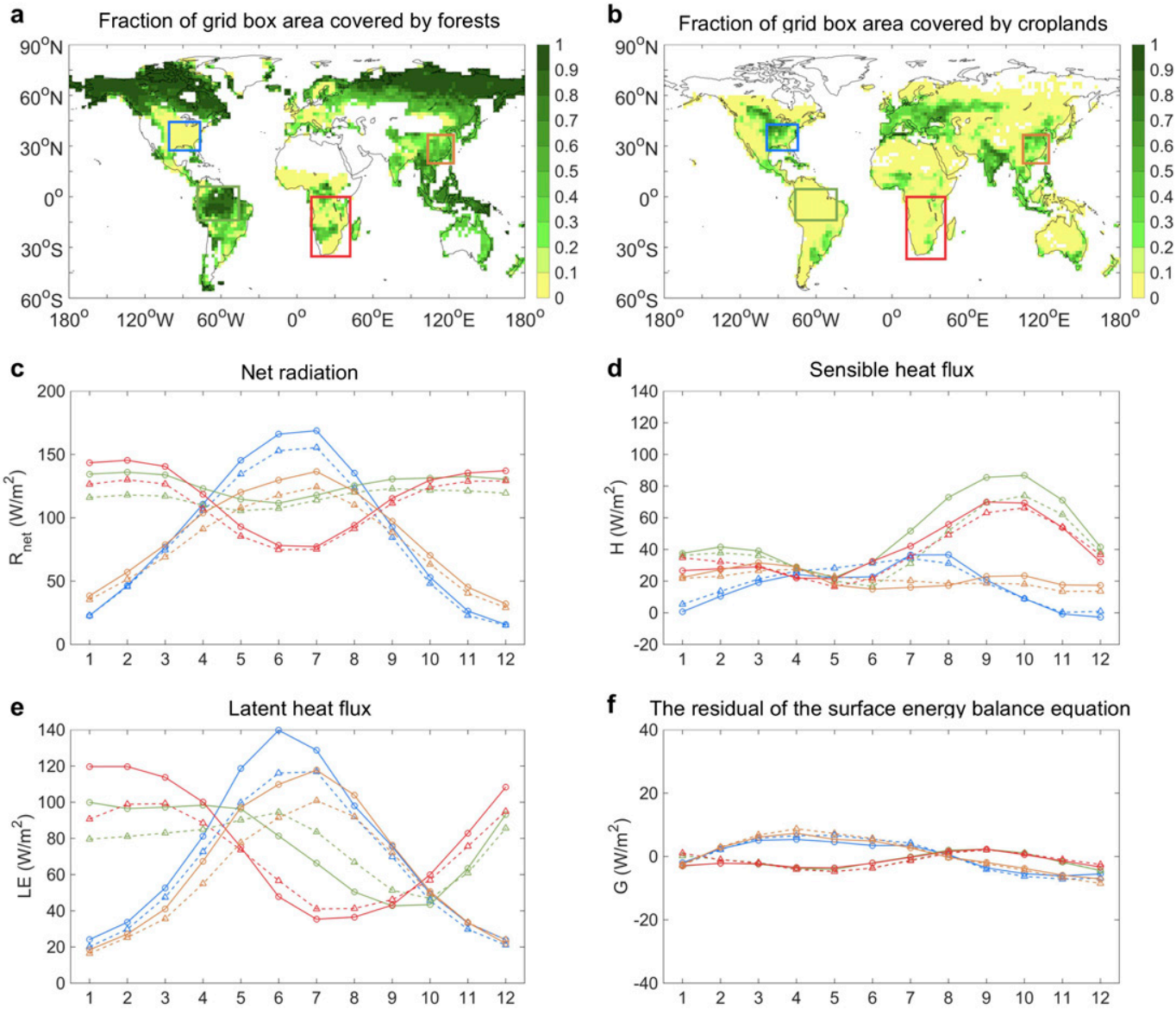

FIG. 1. Fractions of (a) forests and (b) croplands averaged over 1980-2005, and the seasonal cycles of (c) net surface radiation $\left(R_{\text {net }}\right)$, (d) sensible heat flux $(H)$, (e) latent heat flux $(L E)$, and (f) the residual of the surface energy balance $(G)$ averaged over eastern America (blue), Amazon (green), southern Africa (red), and eastern China (orange) in the GFDL-ESM2Mb model. Solid lines represent forests and dashed lines represent croplands.

$$
\begin{aligned}
S_{\mathrm{in}}(1-\alpha)+\varepsilon L_{\mathrm{in}}-\varepsilon \sigma T_{s}^{4}= & \frac{\rho c_{p}}{r_{a}}\left(T_{s}-T_{a}\right) \\
& +\frac{\rho L_{v}}{r_{a}+r_{s}}\left[q_{s}^{*}\left(T_{s}\right)-q_{a}\right]+G .
\end{aligned}
$$

Linearizing the outgoing longwave radiation and saturated specific humidity terms at the air temperature yields

$$
T_{s}=\frac{R_{n}^{*}-G-\frac{\rho L_{v}}{r_{a}+r_{s}}\left[q_{a}^{*}\left(T_{a}\right)-q_{a}\right]}{\frac{1}{\lambda_{0}}+\frac{\rho c_{p}}{r_{a}}+\left.\frac{\rho L_{v}}{r_{a}+r_{s}} \frac{\partial q^{*}}{\partial T}\right|_{T_{a}}}+T_{a},
$$

where $R_{n}^{*}=S_{\text {in }}(1-\alpha)+\varepsilon L_{\text {in }}-\varepsilon \sigma T_{a}^{4}$ and $\lambda_{0}=1 /\left(4 \varepsilon \sigma T_{a}^{3}\right)$. Further denoting $r_{0}=\rho c_{p} \lambda_{0}, \psi=\partial e * /\left.\partial T\right|_{T_{a}}, \gamma=c_{p} P /$ $\left(0.622 L_{v}\right)$, and $f=\left(r_{0} / r_{a}\right)\left\{1+(\psi / \gamma)\left[r_{a} /\left(r_{a}+r_{s}\right)\right]\right\}$ leads to

$$
T_{s}=\frac{\lambda_{0}\left\{R_{n}^{*}-G-\frac{\rho L_{v}}{r_{a}+r_{s}}\left[q_{a}^{*}\left(T_{a}\right)-q_{a}\right]\right\}}{1+f}+T_{a} .
$$

With an analytical expression for LST [i.e., Eq. (6)], now we can compute the responses of LST to perturbations on any factors (e.g., albedo) that appear on the rhs of Eq. (6). Previous applications of the TRM method were limited to analyzing LST changes induced by changes in biophysical factors ( $\mathrm{Li}$ et al. 2019; Rigden and Li 2017). However, changes in atmospheric conditions can also induce LST changes (Moon et al. 2020; Wang et al. 2019; Liao et al. 2018). After identifying all key biophysical and atmospheric factors in Eq. (6), we improve the original TRM method to attribute the LST change $\left(\Delta T_{s}\right)$ to changes in the albedo, emissivity, aerodynamic resistance, surface resistance, heat storage, atmosphere specific humidity, air temperature, incoming shortwave 

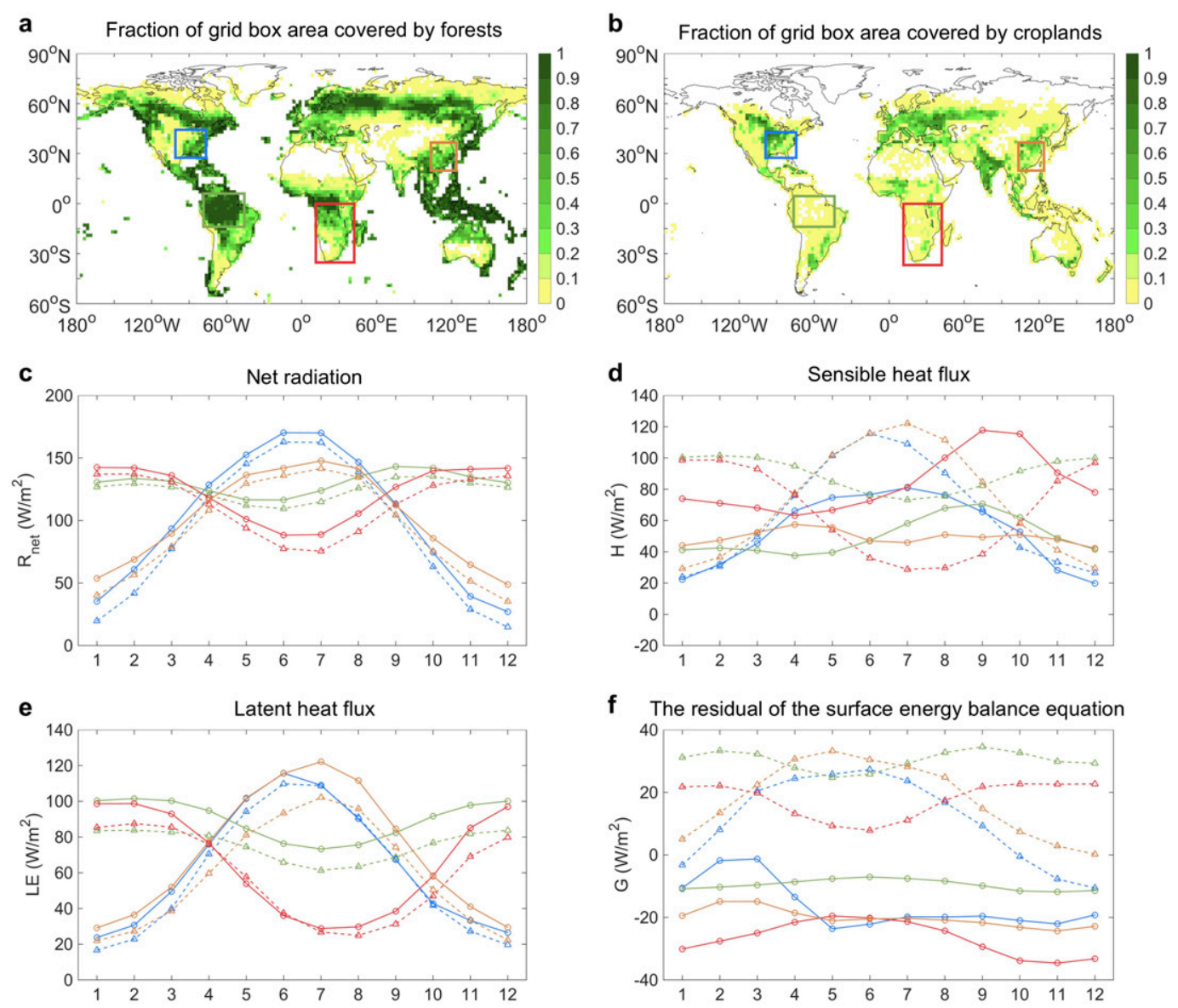

FIG. 2. As in Fig. 1, but for the CESM model.

radiation, and incoming longwave radiation. Detailed formulations are shown as follows:

$$
\begin{aligned}
\Delta T_{s}= & \frac{\partial T_{s}}{\partial \alpha} \Delta \alpha+\frac{\partial T_{s}}{\partial \varepsilon} \Delta \varepsilon+\frac{\partial T_{s}}{\partial r_{a}} \Delta r_{a}+\frac{\partial T_{s}}{\partial r_{s}} \Delta r_{s}+\frac{\partial T_{s}}{\partial G} \Delta G \\
& +\frac{\partial T_{s}}{\partial q_{a}} \Delta q_{a}+\frac{\partial T_{s}}{\partial T_{a}} \Delta T_{a}+\frac{\partial T_{s}}{\partial S_{\mathrm{in}}} \Delta S_{\mathrm{in}}+\frac{\partial T_{s}}{\partial L_{\mathrm{in}}} \Delta L_{\mathrm{in}},
\end{aligned}
$$

where

$$
\begin{aligned}
& \frac{\partial T_{s}}{\partial \alpha}=-\frac{\lambda_{0}}{1+f} S_{\mathrm{in}} \\
& \frac{\partial T_{s}}{\partial \varepsilon}=\frac{\lambda_{0}}{1+f}\left\{L_{\mathrm{in}}-\sigma T_{a}^{4}-\frac{R_{n}^{*}-G-\frac{\rho L_{v}}{r_{a}+r_{s}}\left[q_{a}^{*}\left(T_{a}\right)-q_{a}\right]}{\varepsilon(1+f)}\right\}
\end{aligned}
$$

$$
\begin{aligned}
\frac{\partial T_{s}}{\partial r_{a}} & =\frac{\lambda_{0}}{1+f}\left(\frac{\rho L_{v}\left[q_{a}^{*}\left(T_{a}\right)-q_{a}\right]}{\left(r_{a}+r_{s}\right)^{2}}+\frac{\lambda_{0}}{1+f}\left\{R_{n}^{*}-G\right.\right. \\
& \left.\left.-\frac{\rho L_{v}\left[q_{a}^{*}\left(T_{a}\right)-q_{a}\right]}{r_{a}+r_{s}}\right\}\left[\frac{\rho c_{p}}{r_{a}^{2}}+\frac{\delta}{\gamma} \frac{\rho c_{p}}{\left(r_{a}+r_{s}\right)^{2}}\right]\right), \\
\frac{\partial T_{s}}{\partial r_{s}} & =\frac{\lambda_{0}}{1+f}\left(\frac{\rho L_{v}\left[q_{a}^{*}\left(T_{a}\right)-q_{a}\right]}{\left(r_{a}+r_{s}\right)^{2}}+\frac{\lambda_{0}}{1+f}\left\{R_{n}^{*}-G\right.\right. \\
& \left.\left.-\frac{\rho L_{v}\left[q_{a}^{*}\left(T_{a}\right)-q_{a}\right]}{r_{a}+r_{s}}\right\} \frac{\delta}{\gamma} \frac{\rho c_{p}}{\left(r_{a}+r_{s}\right)^{2}}\right), \\
\frac{\partial T_{s}}{\partial G} & =-\frac{\lambda_{0}}{1+f}, \\
\frac{\partial T_{s}}{\partial q_{a}} & =\frac{\lambda_{0}}{(1+f)} \frac{\rho L_{v}}{\left(r_{a}+r_{s}\right)},
\end{aligned}
$$


a

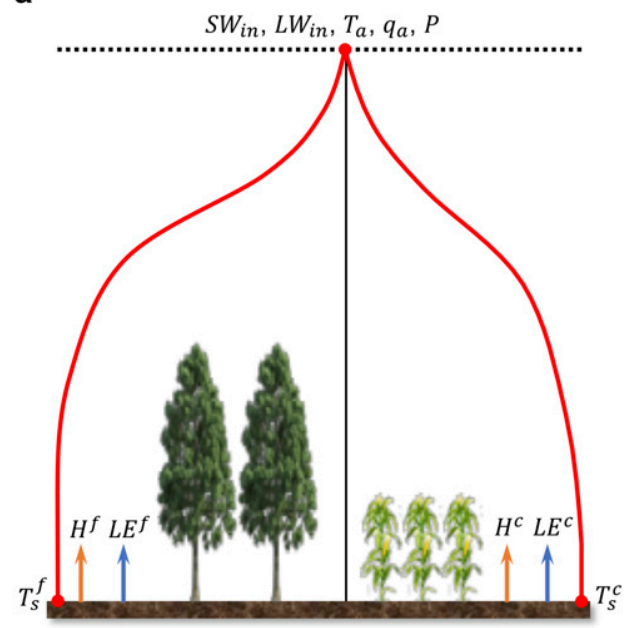

b

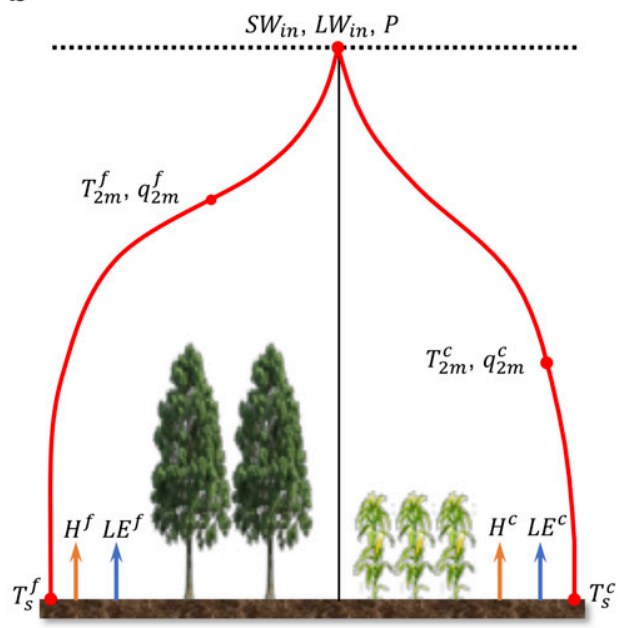

FIG. 3. A schematic diagram illustrating the attribution of subgrid temperature contrast as the required atmospheric inputs of the attribution method. For simplicity, only two tiles, e.g., forest (superscript $f$ ) and cropland (superscript $c$ ), are shown. (a) The situation where atmospheric temperature $\left(T_{a}\right)$ and humidity $\left(q_{a}\right)$ are from the lowest level of the atmospheric model; (b) the situation where atmospheric temperature and humidity are from the reference levels (often at $2 \mathrm{~m}$ above the displacement height, viz., $T_{2 \mathrm{~m}}$ and $q_{2 \mathrm{~m}}$ ).

$$
\begin{aligned}
\frac{\partial T_{s}}{\partial T_{a}=} & \frac{f}{1+f}-\frac{0.622 \delta \lambda_{0} \rho L_{v}}{P(1+f)\left(r_{a}+r_{s}\right)} \\
& +\frac{\lambda_{0}\left\{R_{n}^{*}-G-\frac{\rho L_{v}}{r_{a}+r_{s}}\left[q_{a}^{*}\left(T_{a}\right)-q_{a}\right]\right\}}{1+f} \\
& \times\left[\frac{1}{\lambda_{0}} \frac{\partial \lambda_{0}}{\partial T_{a}}-\frac{1}{(1+f)} \frac{\partial f}{\partial T_{a}}\right], \\
\frac{\partial \lambda_{0}}{\partial T_{a}}= & -\frac{3}{4 \varepsilon \sigma T_{a}^{4}}, \\
\frac{\partial f}{\partial T_{a}}= & \frac{\rho c_{p}}{r_{a}}\left[1+\frac{\delta}{\gamma}\left(\frac{r_{a}}{r_{a}+r_{s}}\right)\right] \frac{\partial \lambda_{0}}{\partial T_{a}}+\frac{r_{0}}{\gamma\left(r_{a}+r_{s}\right)} \frac{\partial \delta}{\partial T_{a}}, \\
\frac{\partial T_{s}}{\partial S_{\text {in }}}= & \frac{\lambda_{0}}{1+f}(1-\alpha), \\
\frac{\partial T_{s}}{\partial L_{\text {in }}}= & \frac{\lambda_{0} \varepsilon}{1+f} .
\end{aligned}
$$

In Eq. (7), $\Delta$ represents a change (e.g., the difference between forests and croplands, which is calculated as croplands minus forests in our study to represent the deforestation effect). Each term on the rhs of Eq. (7) will be called a contribution, which composes of a sensitivity (the partial derivative) and a change ( $\Delta$ ). In our study, the emissivity is assumed to be the same $(=0.98)$ for different land-cover types, and therefore $\Delta \varepsilon$ is simply zero in Eq. (7).
The required inputs for the attribution method include variables from the land (including the outgoing shortwave radiation, sensible heat flux, latent heat flux, and LST) and the atmosphere (including the incoming shortwave and longwave radiation, air pressure, air temperature, and specific humidity). These required variables are available from the GFDL-ESM2Mb model and the CESM model.

Here it is important to distinguish the difference between air temperature and humidity at the lowest level of the atmospheric models and their counterparts at the reference level (typically $2 \mathrm{~m}$ above the displacement height, see Fig. 3b), both of which can be used in our attribution framework [Eq. (7)]. Both the GFDLESM2Mb and the CESM models assume that the surface variabilities have no direct effect on the background state above the lowest level of the atmospheric models (i.e., one can view the lowest level of the atmospheric model as above the so-called blending height). If the air temperature and humidity at the lowest level of the atmospheric models are used in our attribution framework, their differences between croplands and forests are simply zero (Fig. 3a). However, if the air temperature and humidity at the reference level are used, the differences between croplands and forests are nonzero (Fig. 3b). For atmospheric variables other than air temperature and humidity (viz., the incoming shortwave and longwave radiation and air pressure), such distinction is not needed as they are typically output only at the lowest level of the atmospheric models. 
In this study, the atmospheric variables from the GFDL-ESM2Mb model simulation were output at the lowest level of its atmospheric model and hence they are identical for croplands and forests. Therefore, Eq. (7) can be simplified as

$$
\Delta T_{s}=\frac{\partial T_{s}}{\partial \alpha} \Delta \alpha+\frac{\partial T_{s}}{\partial r_{a}} \Delta r_{a}+\frac{\partial T_{s}}{\partial r_{s}} \Delta r_{s}+\frac{\partial T_{s}}{\partial G} \Delta G
$$

However, the CESM model output the reference-level air temperature and specific humidity for each PFT, which are different for forests and croplands. In this case, Eq. (7) can be simplified as

$$
\begin{aligned}
\Delta T_{s}= & \frac{\partial T_{s}}{\partial \alpha} \Delta \alpha+\frac{\partial T_{s}}{\partial r_{a}} \Delta r_{a}+\frac{\partial T_{s}}{\partial r_{s}} \Delta r_{s}+\frac{\partial T_{s}}{\partial G} \Delta G \\
& +\frac{\partial T_{s}}{\partial q_{a}} \Delta q_{a}+\frac{\partial T_{s}}{\partial T_{a}} \Delta T_{a} .
\end{aligned}
$$

In retrospect, saving the temperature and humidity at the lowest level of its atmospheric model for the CESM model simulation would have enabled a more consistent comparison between the two models. However, we point out that some simulations might only save the reference-level air temperature and humidity. As such, being able to compare two models (and potentially other models) using the same framework [Eq. (7)] but with slightly different simplifications [Eq. (19) vs Eq. (20)] due to the differences in the atmospheric variables that can be obtained is still meaningful.

Before we perform such attribution analyses, it is critical to ensure acceptable agreement between the $\Delta T_{s}$ directly computed by the GFDL-ESM $2 \mathrm{Mb}$ and the CESM models and the modeled $\Delta T_{s}$ by the attribution method [Eq. (7)]. To assess the performance of the attribution method in capturing $\Delta T_{s}$, we use the rootmean-square error (RMSE) between the $\Delta T_{s}$ from the GFDL-ESM2Mb and the CESM models and the $\Delta T_{s}$ modeled by the attribution method.

To do so, we need to understand the limitations of the attribution method. First, the parameterizations of turbulent heat fluxes should in theory only work when the aerodynamic resistance and the surface resistance are positive. Hence, if the inferred aerodynamic resistance and/or surface resistance based on Eqs. (2) and (3) are negative, the data are not considered. Second, the inferred aerodynamic and surface resistances have large uncertainties when the sensible or latent heat flux is very small. Therefore, we exclude months if the absolute values of monthly sensible and latent heat fluxes are less than $5 \mathrm{~W} \mathrm{~m}^{-2}$. Last but not the least, the attribution method is based on first-order Taylor's series expansion. Neglecting higher-order terms in the Taylor's series expansion [Eq. (7)] can also introduce large errors when the perturbations are large (Liao et al. 2018). To improve the accuracy of the attribution method, we use a weighted approach to calculate the partial derivatives in Eq. (7) based on variables from the forest and cropland tiles, as follows:

$$
Y=\frac{Y_{\text {forest }}+m Y_{\text {cropland }}}{1+m}
$$

where $Y$ is the final partial derivative used in the attribution model, $m$ is the weight, and $Y_{\text {forest }}$ and $Y_{\text {cropland }}$ are the partial derivatives calculated using the information from forests and croplands, respectively. The values of the weight $m$ are optimized by minimizing the RMSE in each grid cell. Figure S1 in the online supplemental material shows the optimized $m$ values in the GFDL-ESM2Mb and the CESM models. After the optimization, the RMSE values are generally smaller than $0.2^{\circ} \mathrm{C}$ (Fig. S2). Taking the results of the GFDLESM2Mb model in summer as an example, the mean value of the direct $\Delta T_{s}$ is $0.93^{\circ} \pm 0.91^{\circ} \mathrm{C}$ (the mean plus and minus one standard deviation), while the RMSE is $0.15^{\circ} \mathrm{C}$, which is only $16 \%$ of the mean value. It implies that the attribution method can capture changes in LST well at the global scale.

Throughout the paper, two metrics are defined to quantify the differences between the GFDL-ESM2Mb model and the CESM model, as follows:

$$
\begin{aligned}
& \delta=V_{\mathrm{GFDL}}-V_{\mathrm{CESM}}, \\
& \tilde{\delta}=\left|\frac{V_{\mathrm{GFDL}}-V_{\mathrm{CESM}}}{V_{\mathrm{CESM}}}\right| \times 100 \%,
\end{aligned}
$$

where $\delta$ is called the difference between the two models in terms of variable $V$ and $\tilde{\delta}$ is called the fractional difference, with $V_{\mathrm{GFDL}}$ and $V_{\mathrm{CESM}} \delta$ being the values of $V$ in the GFDL-ESM2Mb and the CESM models, respectively. Note that for the fractional difference, we only consider the absolute magnitude.

\section{Results and discussion}

\section{a. The impacts of deforestation on surface fluxes in the GFDL-ESM2Mb and the CESM models}

The seasonal cycles of net surface radiation $\left(R_{\text {net }}\right)$, sensible heat flux $(H)$, latent heat flux $(L E)$, and ground heat flux $(G)$, which is calculated as the residual of the surface energy balance (i.e., $G=R_{\text {net }}-H-L E$ ), averaged over four regions (i.e., eastern North America, the Amazon, southern Africa, and eastern China), are shown in Figs. 1 and 2 for the GFDL-ESM2Mb model 
and the CESM model, respectively. For a given model, although the incoming solar radiation is identical, forests and croplands have substantially different seasonal cycles of the net radiation, sensible heat flux, and latent heat flux. For instance, more net radiation is received by forests, especially during summer, which is related to the lower albedo of forests than croplands (Figs. 1c and 2c). Additionally, the latent heat flux of forests is larger than that of croplands during summer (Figs. 1e and 2e). These features are similar in both models and are expected given the biophysical differences between forests and croplands.

However, the seasonal patterns in sensible heat flux and ground heat flux differ considerably between the two models. In the GFDL-ESM2Mb model, the seasonal cycles of sensible heat flux are synchronized for forests and croplands, with the sensible heat flux of forests larger than that of croplands (Fig. 1d). Moreover, the ground heat flux is close to zero (Fig. 1f). On the other hand, forests and croplands have different seasonal patterns of sensible heat flux and the ground heat flux significantly differs from zero in the CESM model (Figs. 2d,f). The long-term-averaged ground heat flux is expected to be rather small but is fairly large in the CESM model, which has been traced to the column configuration used in the Community Land Model (CLM 4.5) of CESM (Schultz et al. 2016). Specifically, all PFTs share the same soil column in the CLM 4.5 model, which is not the case in the land model (LM3) of GFDL-ESM2Mb. The difference between the two models in terms of ground heat flux implies that model structures can have an important impact on the PFT-level energy fluxes.

Overall, forests and croplands have large differences in terms of radiative and turbulent fluxes (Figs. 1 and 2), which are caused by their contrasting surface biophysical properties (e.g., albedo). These different biophysical properties further result in different LSTs. With the caveat that the two models have different structures in mind, in the following we decompose the LST differences between forests and croplands into contributions from different factors based on the improved attribution framework described earlier.

\section{b. Attribution of the LST response to deforestation in the GFDL-ESM2Mb model}

Using subgrid outputs from the GFDL-ESM2Mb model and the improved attribution method, we attribute the LST contrast between forests and croplands to changes in albedo, aerodynamic resistance, surface resistance, and heat storage [Eq. (19)]. Figures 4 and 5 show the attribution results during summer (JJA for the Northern Hemisphere and DJF for the Southern Hemisphere). First of all, it can be seen that the $\Delta T_{s}$ modeled by the attribution method shows good agreement with the $\Delta T_{s}$ calculated directly by taking the temperature difference between forests and croplands (croplands minus forests) in the GFDL-ESM2Mb model (Figs. 4a,b). Similar to the findings in Malyshev et al. (2015), converting forests to croplands results in warming during summer. The LST differences between forests and croplands are on the order of $+0.5^{\circ} \mathrm{C}$ over most places and up to $+2.0^{\circ} \mathrm{C}$ in some regions (e.g., eastern Rocky Mountains, India, and western China). In terms of latitudinal variations, the $\Delta T_{s}$ is larger in the midlatitudes (around $30^{\circ} \mathrm{N}$ and $30^{\circ} \mathrm{S}$ ) and relatively smaller in the high latitudes and the tropics.

Similar to the findings in previous observational and modeling studies (Chen and Dirmeyer 2016; Lee et al. 2011), the warming effect of deforestation can be largely explained by changes in aerodynamic resistance in terms of magnitude (Fig. 5) and spatial pattern (Fig. 4). Because forests are aerodynamically rougher than croplands, they transfer heat more efficiently from the surface to the atmosphere and thus experience lower LST than croplands (Liao et al. 2018; Burakowski et al. 2018; Chen and Dirmeyer 2016; Lee et al. 2011; Rotenberg and Yakir 2011). It should be noted that we did not examine the diurnal cycle of LST changes. Previous studies indicate that the dominant role of aerodynamic resistance is mainly in the daytime when the surface is typically hotter than the atmosphere (Burakowski et al. 2018; Chen and Dirmeyer 2016).

On the other hand, changes in albedo lead to a cooling effect of deforestation as forests absorb more solar radiation due to lower albedo (Fig. 4c). This cooling effect increases at higher latitudes in the Northern Hemisphere. Contributions to LST changes from changes in surface resistance are inhomogeneous across the globe, with a cooling effect near the northern high latitudes and over many other regions (e.g., northern America, the Amazon, southern Africa, and western China) but a warming effect over parts of central America, India, southern Asia, and Oceania (Fig. 4e). Contributions from changes in heat storage are close to zero, which is expected given that these results are averaged over the period 1980 2005 (Fig. 4f).

In the winter season, poor data quality in the northern high latitudes limits analysis and interpretation of model results (Fig. S3). At lower latitudes, croplands show larger LSTs in the tropics but smaller LSTs in the midlatitudes, especially in eastern Rocky Mountains, Europe, northern Africa, and the southern part of South America. Similar to the results in summer, the LST differences between forests and croplands are also mainly controlled by changes in aerodynamic resistance in winter (Fig. S4). However, in some places the warming effect of 
a
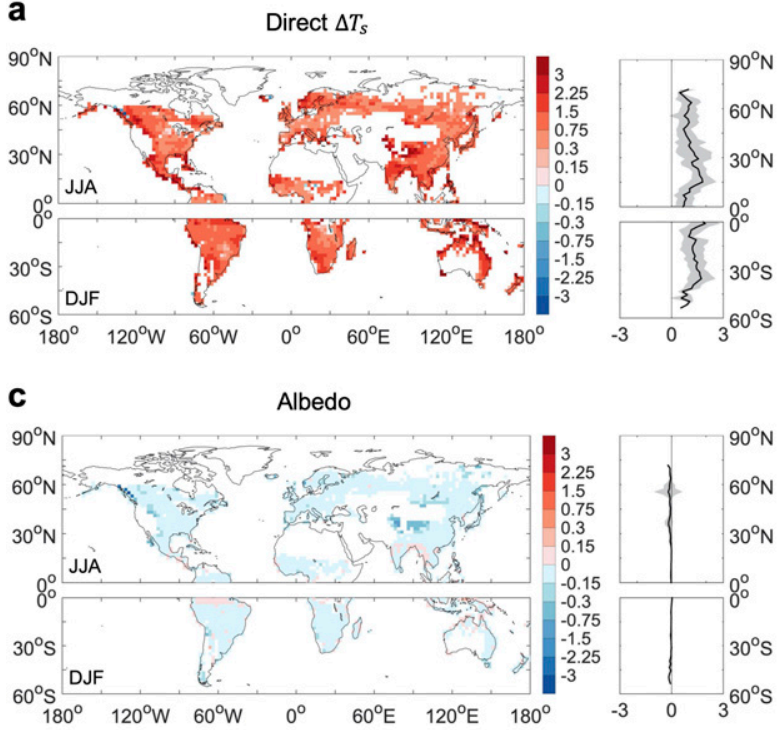

e

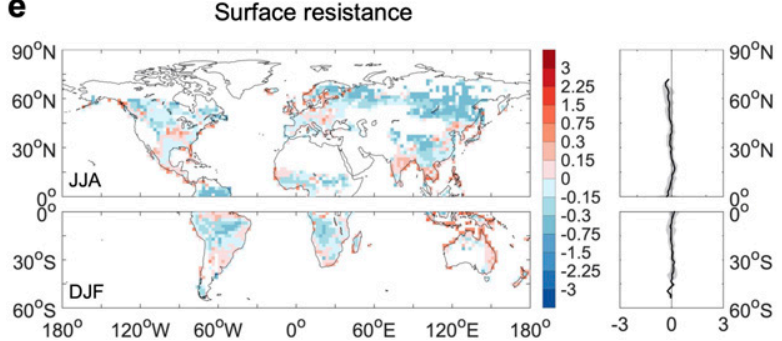

b

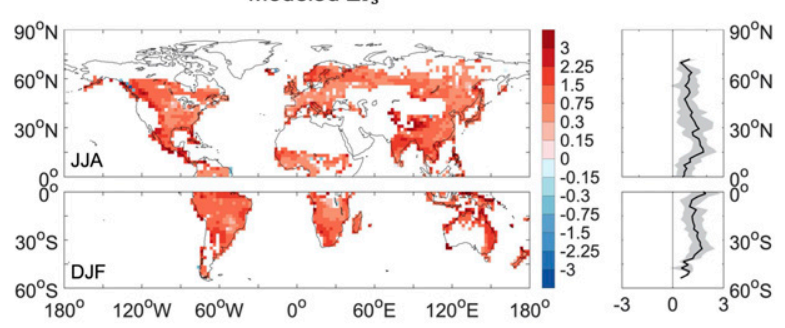

d

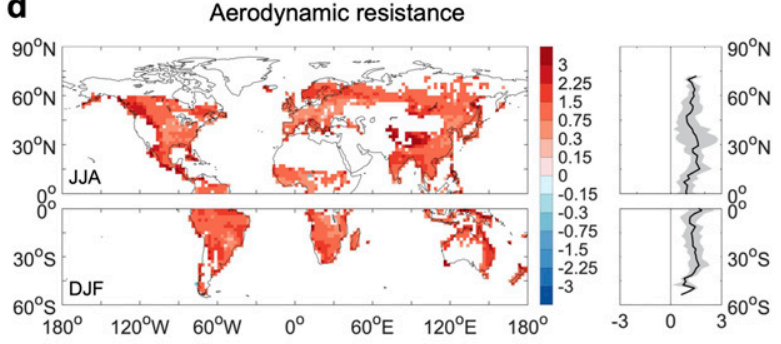

f

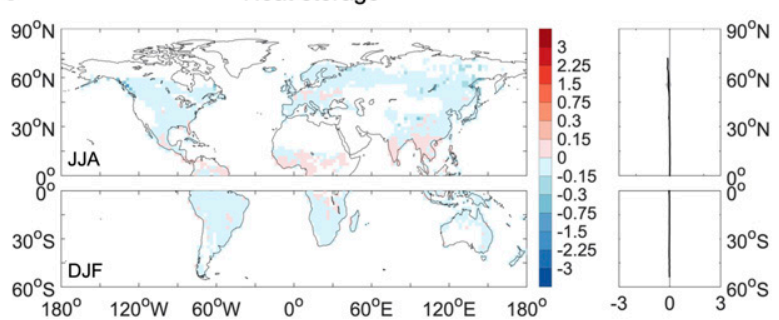

FIG. 4. Attribution of the LST contrast between forests and croplands ( $\Delta=$ cropland - forest) during summer in the GFDL-ESM2Mb model. (a) The direct $\Delta T_{s}$ calculated by taking the temperature difference between forests and croplands in the GFDL-ESM2Mb model simulation and (b) the modeled $\Delta T_{s}$ computed by the attribution method. Contributions to the LST contrast from changes in the (c) albedo, (d) aerodynamic resistance, (e) surface resistance, and (f) heat storage based on the attribution method. The information in (b) corresponds to the term on the lhs of Eq. (19) while (c)-(f) correspond to, in order, the terms on the rhs of Eq. (19). For the Northern and Southern Hemispheres, the figure shows the JJA and DJF averages, respectively. The black line denotes the latitudinal dependence of the corresponding value and the gray shading represents the mean \pm 1 standard deviation of the corresponding value. Units are ${ }^{\circ} \mathrm{C}$.

deforestation induced by changes in aerodynamic resistance can be overwhelmed by the cooling effects induced by changes in albedo and surface resistance in winter (e.g., over northern Africa and the southern part of South America). Overall, although the spatial patterns of LST differences are different in summer and winter, the key biophysical factor controlling LST differences between forests and croplands is aerodynamic resistance in the GFDL-ESM2Mb model.

\section{c. Attribution of the LST response to deforestation in the CESM model}

Using subgrid outputs from the CESM model and the improved attribution method, we attribute the LST contrast between forests and croplands to changes in albedo, aerodynamic resistance, surface resistance, heat storage, specific humidity, and air temperature [Eq. (20), see Figs. 6 and 7 ]. In summer, the $\Delta T_{s}$ modeled by the attribution method shows good agreement with the $\Delta T_{s}$ computed directly from the model simulation (Figs. 6a,b), suggesting that the attribution method captures $\Delta T_{s}$ reasonably well. Changing forests to croplands has a cooling effect on LST near the northern high latitudes and over eastern America, India, and eastern China but a warming effect over other regions. The increase in LST from forests to croplands is larger than $+1.5^{\circ} \mathrm{C}$ over western America and southern Europe. Similar to the results from the GFDL-ESM2Mb model, the $\Delta T_{s}$ is larger in the midlatitudes (around $30^{\circ} \mathrm{N}$ and $30^{\circ} \mathrm{S}$ ) and smaller in the tropics and the high latitudes.

The cooling effects from changes in albedo increase at higher latitudes in the Northern Hemisphere, with the maximum contribution up to $-0.5^{\circ} \mathrm{C}$ (Fig. 6c). The contributions from changes in aerodynamic resistance 


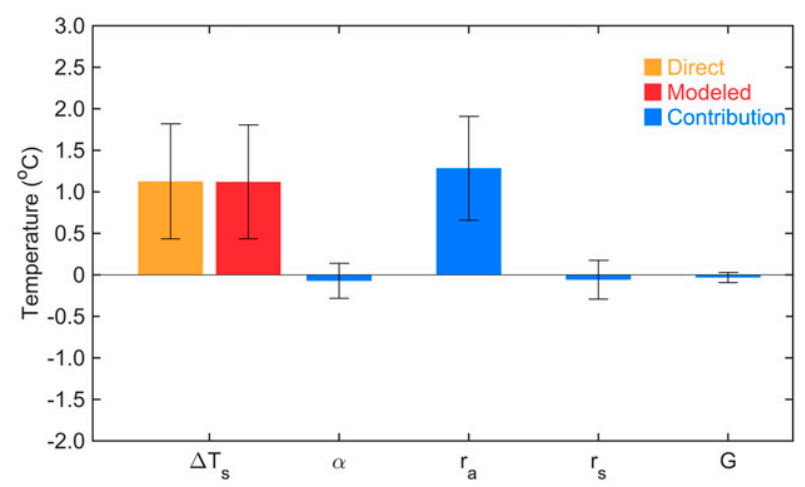

FIG. 5. Global averages of the attribution results for the LST contrast between forests and croplands $(\Delta=$ cropland - forest $)$ during summer in the GFDL-ESM2Mb model. The yellow bar donates the direct $\Delta T_{s}$ calculated by taking the temperature difference between forests and croplands, the red bar denotes the modeled $\Delta T_{s}$ computed by the attribution method, and the blue bars denote the contributions from different biophysical factors. The error bars are given as the standard deviation of the global mean and indicate the spatial variability.

are on the order of $+2.0^{\circ} \mathrm{C}$ over most regions and even up to $+3.0^{\circ} \mathrm{C}$ in the midlatitudes (Fig. $6 \mathrm{~d}$ ). The contributions from changes in surface resistance can be either positive or negative. They are negative over most places but positive over western America, southern Europe, and northern India (Fig. 6e). The contributions from changes in heat storage are smaller than $-1.0^{\circ} \mathrm{C}$ over most regions (Fig. 6f). Furthermore, contributions from changes in atmospheric specific humidity and air temperature are close to zero (Figs. 6g,h). The small contributions from atmospheric specific humidity and air temperature allow us to focus on the biophysical contributions (i.e., from albedo, aerodynamic resistance, surface resistance, and heat storage) that are common to both models, as shall be seen in section $4 \mathrm{~d}$. In summary, although the warming effect induced by changes in aerodynamic resistance can be dampened by the cooling effects induced by changes in albedo, surface resistance and heat storage to some extent, $\Delta T_{s}$ is still positive over most regions, which indicates that changes in aerodynamic resistance play the dominant role in determining LST changes from forests to croplands in summer (Fig. 7). This is consistent with the finding from Fig. 5.

In the winter season, snow cover results in a larger cooling effect from changes in albedo in high latitudes of the Northern Hemisphere than that in summer (Fig. S5). The cooling effects from changes in surface resistance and heat storage are overall large in low latitudes and relatively small in high latitudes. Nevertheless, similar to the results in summer, the warming effects from changes in aerodynamic resistance still control the winter LST changes (Fig. S6).

\section{d. Comparison between results from the GFDL-ESM2Mb and CESM models}

Generally, the LST differences between forests and croplands in the GFDL-ESM2Mb and the CESM models are different, as shown in Fig. 8 and Fig. S7, which present the differences between the two models (GFDL minus CESM) in summer and winter, respectively. During the summer season (see Fig. 8), the LST differences between forests and croplands are larger in the GFDL-ESM2Mb simulation than in the CESM simulation (Figs. 8a,b). When the attribution results from the two models are compared, the magnitude of different contributions is smaller in the GFDL-ESM2Mb model than the magnitude of their counterparts in the CESM model (cf. Figs. 4 and 6, or cf. Figs. 5 and 7). The contributions from the albedo, surface resistance, and heat storage are weaker (i.e., less negative) in the GFDL model and the contribution from the aerodynamic resistance is also weaker (i.e., less positive) in the GFDL model. As a result, the differences in different biophysical factor contributions (GFDL minus CESM) are positive for the albedo, surface resistance, and heat storage, and negative for the aerodynamic resistance (Figs. 8c-f).

In the following, we focus on analyzing the differences between the two models. According to Eq. (7), contributions from different biophysical factors compose of the sensitivities (e.g., $\partial T_{s} / \partial \alpha, \partial T_{s} / \partial r_{a}, \partial T_{s} / \partial r_{s}$, and $\left.\partial T_{s} / \partial G\right)$ and the corresponding changes (e.g., $\Delta \alpha, \Delta r_{a}, \Delta r_{s}$, and $\Delta G)$ between forests and croplands. Hence, we explore whether the dissimilarity between the GFDL-ESM2Mb model and the CESM model comes from the sensitivities or the corresponding changes.

Figures $9 \mathrm{a}$ and $9 \mathrm{~b}$ show the sensitivity of LST to albedo $\left(\partial T_{s} / \partial \alpha\right)$ in the two models in summer. As expected, the sensitivity of LST to albedo is negative over the whole globe (Qu and Hall 2013). Although the spatial pattern of $\partial T_{s} / \partial \alpha$ is overall similar in the two models (e.g., both models reach the minimum values in the midlatitudes), the magnitude of $\partial T_{s} / \partial \alpha$ in the CESM model is slightly larger than that in the GFDL-ESM2Mb model. In winter (Figs. S8a,b), the magnitude of $\partial T_{s} / \partial \alpha$ in the CESM model is also slightly larger than that in the GFDL-ESM2Mb model. However, unlike in summer the minimum values of $\partial T_{s} / \partial \alpha$ occurring in the midlatitudes, the minimum values of $\partial T_{s} / \partial \alpha$ occur in the tropics in winter.

Figures $9 \mathrm{c}$ and $9 \mathrm{~d}$ compare the sensitivity of LST to aerodynamic resistance $\left(\partial T_{s} / \partial r_{a}\right)$ in summer between the two models. The values of $\partial T_{s} / \partial r_{a}$ are positive over the whole globe, indicating that the LST increases as the land surface becomes smoother (i.e., less efficient in transferring heat from the land surface to the lower 


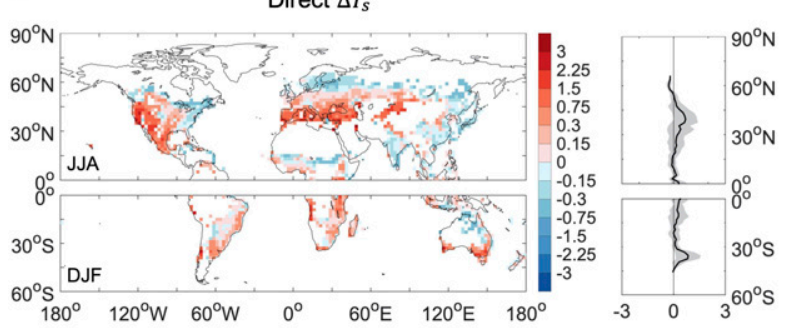

C

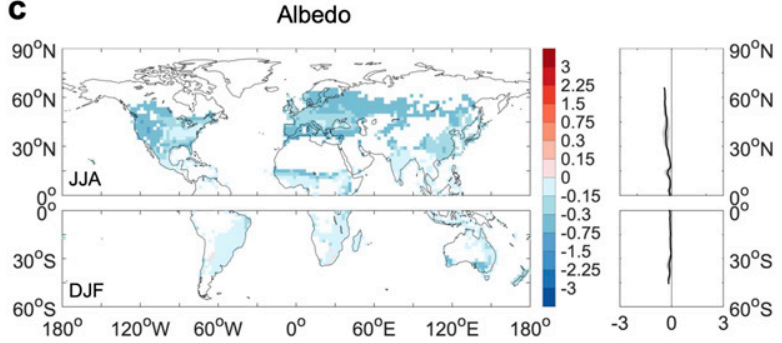

e

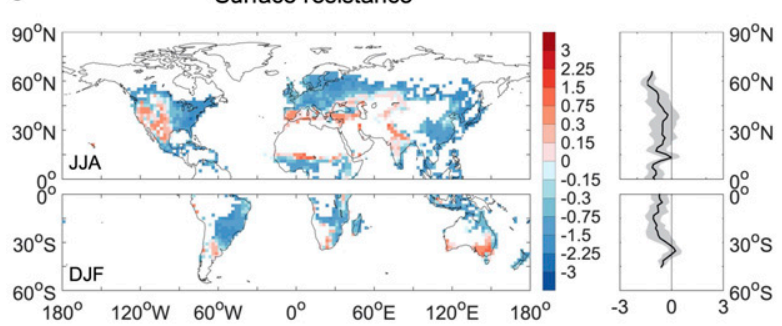

g

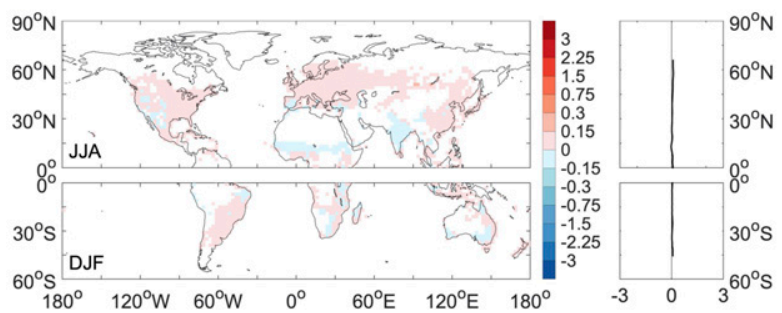

b

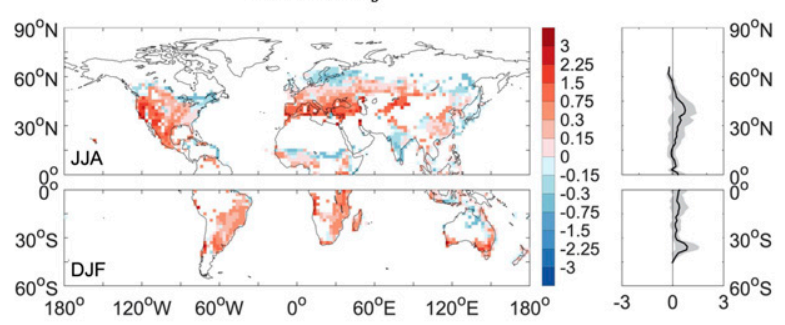

d

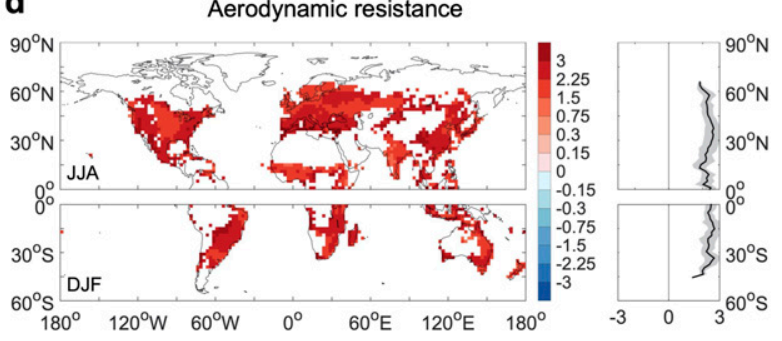

f

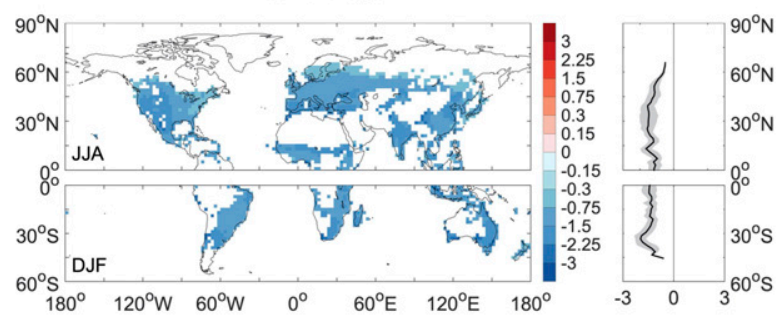

h

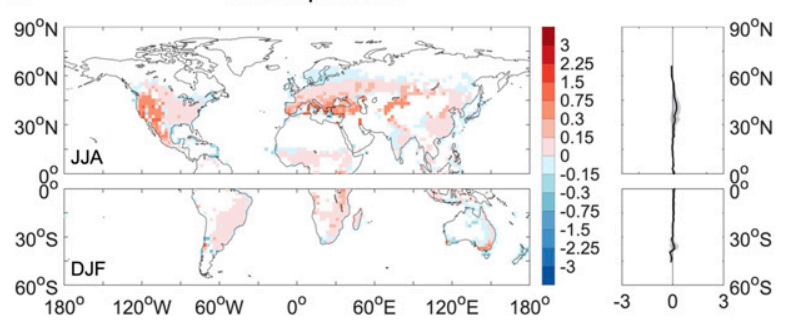

FIG. 6. Attribution of the LST contrast between forests and croplands ( $\Delta=$ cropland - forest) during summer in the CESM model. (a) The direct $\Delta T_{s}$ calculated by taking the temperature difference between forests and croplands in the CESM model simulation and (b) the modeled $\Delta T_{s}$ computed by the attribution method. Contributions to the LST contrast from changes in the (c) albedo, (d) aerodynamic resistance, (e) surface resistance, (f) heat storage, (g) specific humidity, and (h) air temperature based on the attribution method. The information in (b) corresponds to the term on the lhs of Eq. (20) while (c)-(h) correspond to, in order, the first six terms on the rhs of Eq. (20). For the Northern and Southern Hemispheres, the figure shows the JJA and DJF averages, respectively. The black line denotes the latitudinal dependence of the corresponding value and the gray shading represents the mean \pm 1 standard deviation of the corresponding value. Units are ${ }^{\circ} \mathrm{C}$.

atmosphere). The spatial pattern and magnitude of $\partial T_{s} / \partial r_{a}$ are again similar between the two models. The values of $\partial T_{s} / \partial r_{a}$ are larger than $+0.02^{\circ} \mathrm{C} \mathrm{m} \mathrm{s}^{-1}$ over most of regions, and both models reach the maximum values in the midlatitudes. In winter, the values of $\partial T_{s} / \partial r_{a}$ reach the maximum values in the tropics in both models, where the values are larger than $+0.025^{\circ} \mathrm{C} \mathrm{m} \mathrm{s}^{-1}$ (Figs. S8c,d).
Figures $9 \mathrm{e}$ and $9 \mathrm{f}$ compare the sensitivity of LST to surface resistance $\left(\partial T_{s} / \partial r_{s}\right)$ in summer between the two models. The values of $\partial T_{s} / \partial r_{s}$ are positive over the whole globe, indicating that the surface becomes hotter when it becomes drier (less soil moisture or less vegetation). The spatial pattern and magnitude of $\partial T_{s} / \partial r_{s}$ are also similar between the two models. The values are larger than 


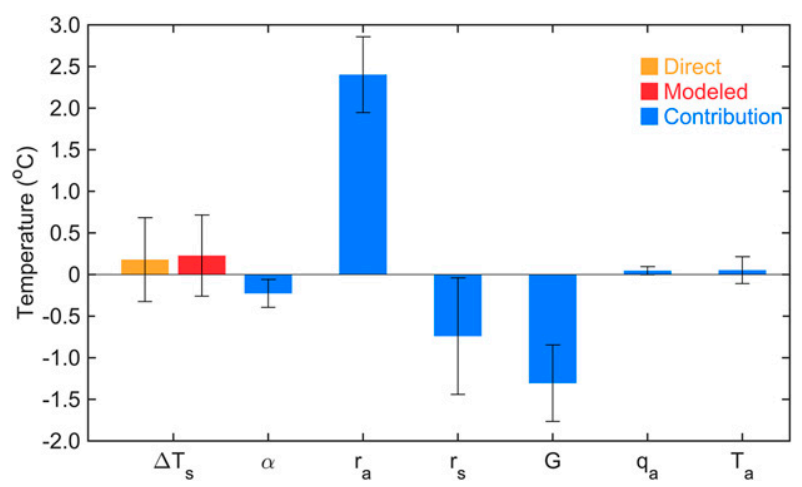

FIG. 7. As in Fig. 5, but in the CESM model.

$+0.004^{\circ} \mathrm{C} \mathrm{m} \mathrm{s}^{-1}$ over most of regions, and both models reach the minimum values in the midlatitudes. In winter, the values of $\partial T_{s} / \partial r_{s}$ are also overall positive over the whole globe, but reach the maximum values (larger than $+0.01^{\circ} \mathrm{C} \mathrm{m} \mathrm{s}^{-1}$ ) in the tropics in both models (Figs. S8e,f).

Figures $9 \mathrm{~g}$ and $9 \mathrm{f}$ show the sensitivity of LST to heat storage $\left(\partial T_{s} / \partial G\right)$ in the two models in summer. The

\section{a}

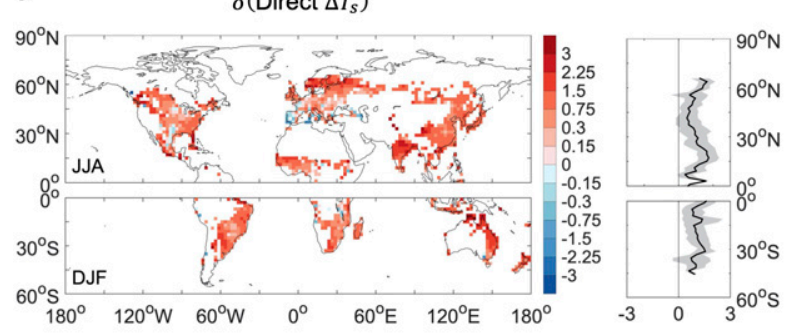

C

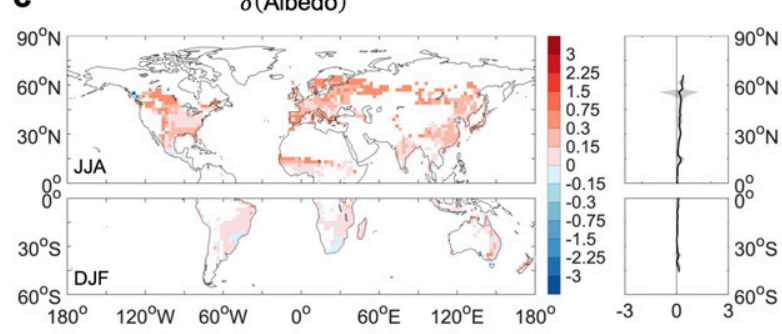

e

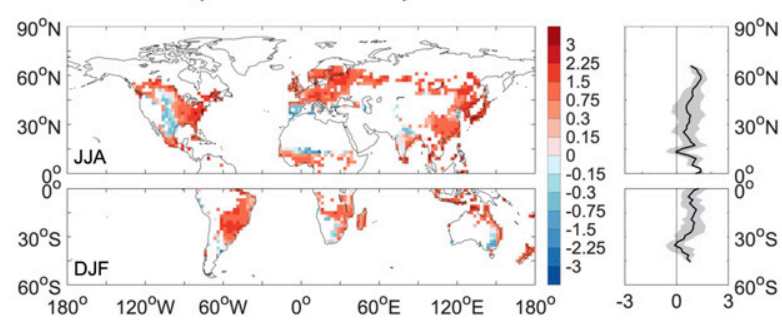

values of $\partial T_{s} / \partial G$ are negative over the whole globe, indicating that the surface becomes cooler when it diverts more energy into the subsurface. The spatial pattern of $\partial T_{s} / \partial G$ is overall similar in the two models but the magnitude of $\partial T_{s} / \partial G$ in the CESM model is relatively larger than that in the GFDL-ESM2Mb model. Similar to the results in summer, the magnitude of $\partial T_{s} / \partial G$ in the CESM model is overall larger than that in the GFDLESM2Mb model in winter (Figs. S8g,f). The slightly stronger sensitivity of LST to heat storage in the CESM model is consistent with the slightly stronger sensitivity of LST to albedo as shown in Figs. 9a and 9b, given that the sensitivity of LST to albedo is simply the sensitivity of LST to heat storage multiplied by the incoming shortwave radiation [cf. Eqs. (8) to (12)].

The various biophysical changes in the GFDL-ESM2Mb and the CESM models during summer and winter are presented in Fig. 10 and Fig. S9, respectively. Generally, both models agree that croplands have higher albedo and aerodynamic resistance values than forests (i.e., positive albedo and aerodynamic resistance changes), implying that deforestation causes the land to be brighter and

b

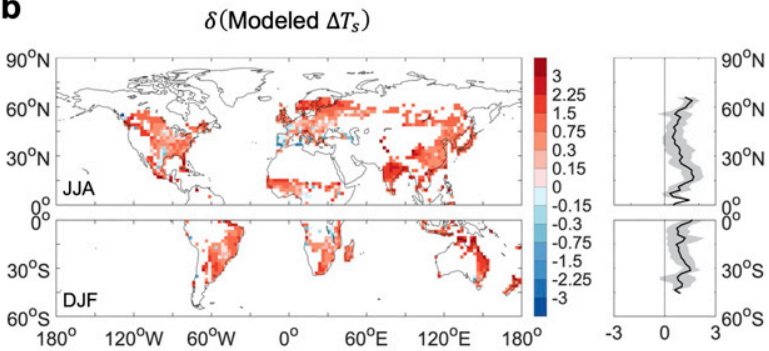

d $\quad \delta$ (Aerodynamic resistance)

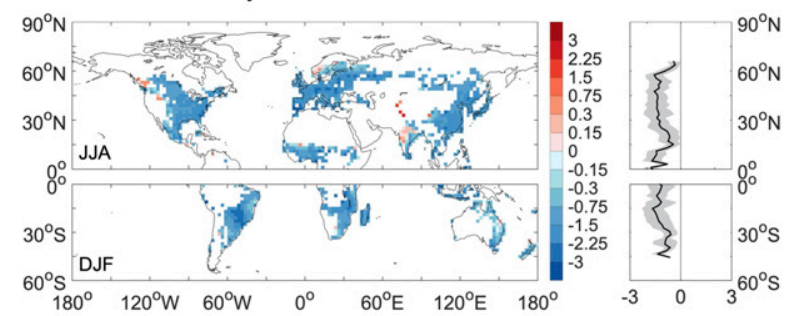

f

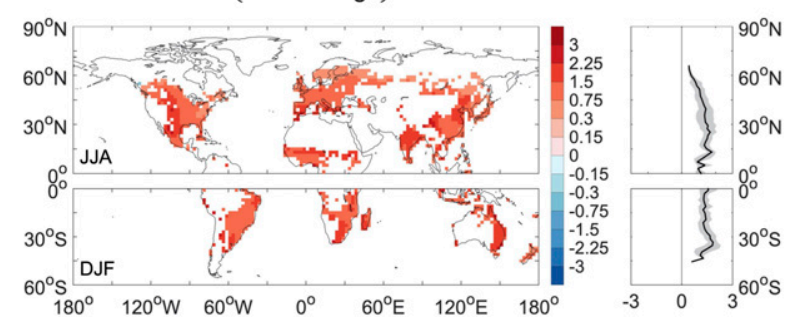

FIG. 8. Differences $(\delta)$ in the attribution results between the GFDL-ESM2Mb and the CESM models (GFDL minus CESM) during summer. Units are ${ }^{\circ} \mathrm{C}$. 


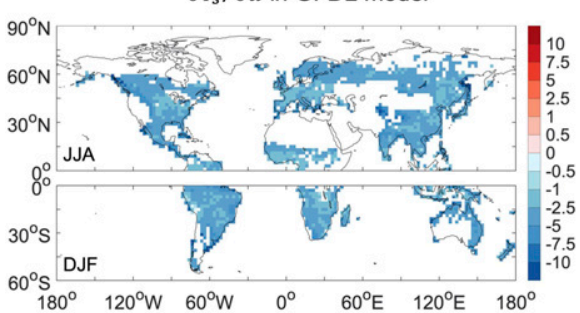

C

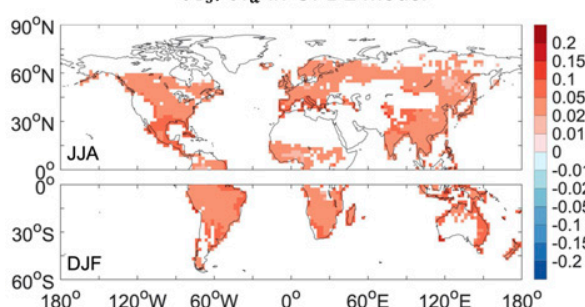

e

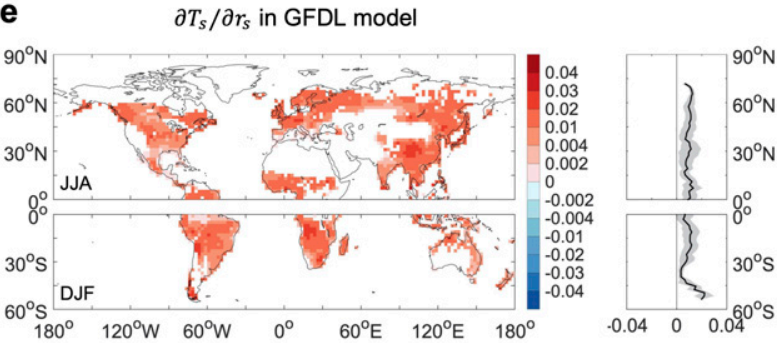

g
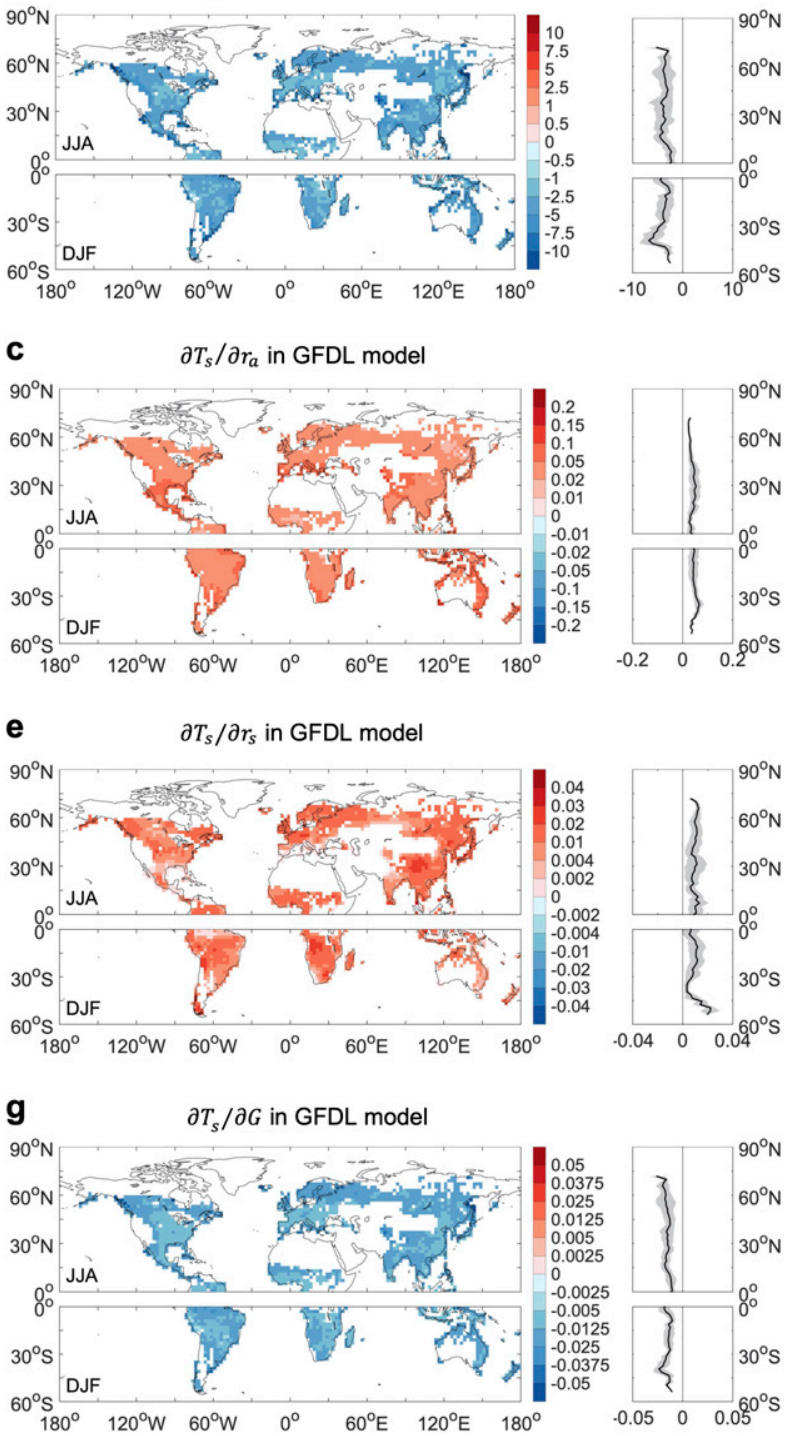

b
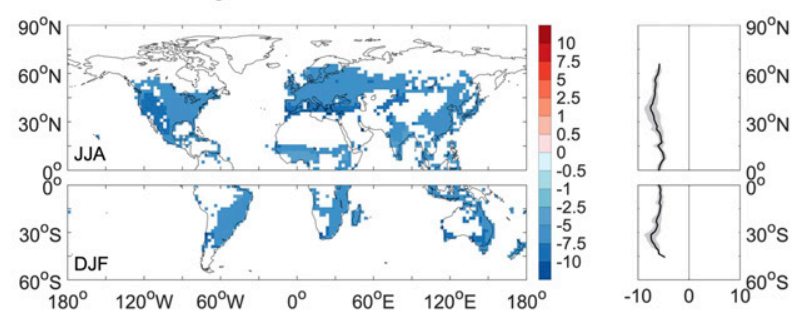

\section{d}
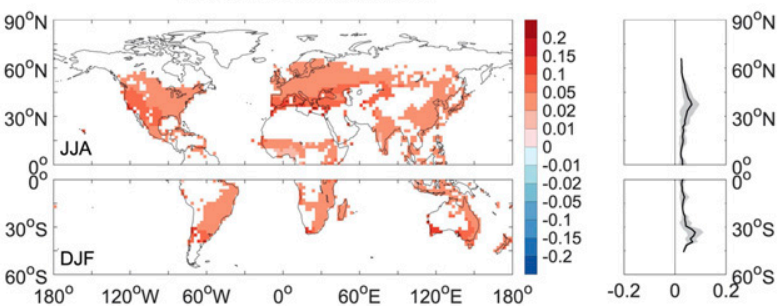

f

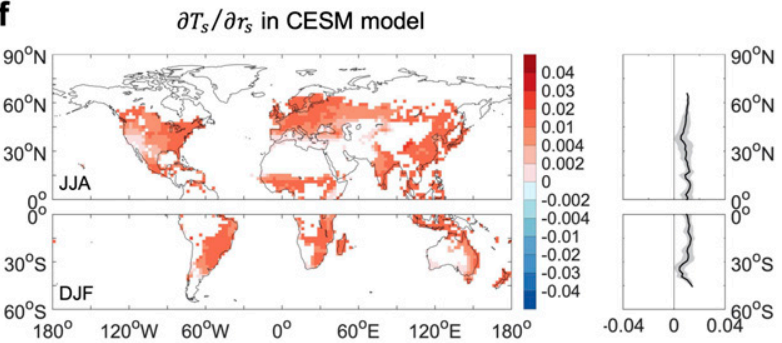

h

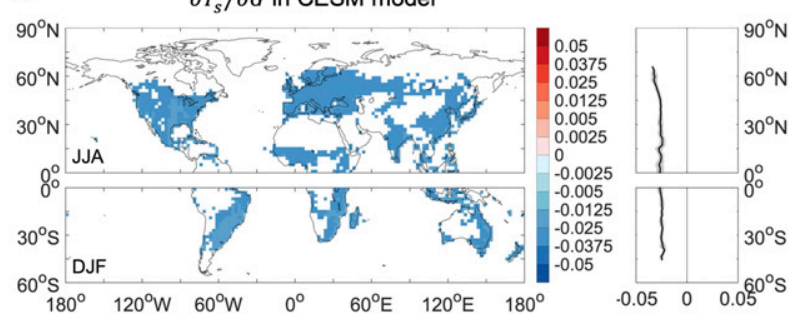

FIG. 9. A comparison of the sensitivities of LST to (a),(b) albedo $\left(\partial T_{s} / \partial \alpha,{ }^{\circ} \mathrm{C}\right),(\mathrm{c}),(\mathrm{d})$ aerodynamic resistance $\left(\partial T_{s} / \partial r_{a},{ }^{\circ} \mathrm{C} \mathrm{m} \mathrm{s}{ }^{-1}\right),(\mathrm{e}),(\mathrm{f})$ surface resistance $\left(\partial T_{s} / \partial r_{s},{ }^{\circ} \mathrm{C} \mathrm{m} \mathrm{s}^{-1}\right)$, and $(\mathrm{g}),(\mathrm{h})$ heat storage $\left(\partial T_{s} / \partial G,{ }^{\circ} \mathrm{C} \mathrm{m}^{2} \mathrm{~W}^{-1}\right)$ in (left) the GFDL-ESM2Mb and (right) the CESM models during summer.

smoother. However, the two models do not agree on the signs of the changes in surface resistance and heat storage. For heat storage changes, the CESM model shows much larger values than the GFDL-ESM2Mb model, which, as discussed earlier, is due to the differences in the model structures. For surface resistance changes, the differences between the two models are possibly due to the substantial difference in the physical parameterizations of evapotranspiration used in the two models (Dunne et al. 2012; Oleson et al. 2013). It is also noted that the two models produce both positive and negative surface resistance changes.
To further quantify the differences between the two models, the differences $(\delta)$ in terms of the sensitivities and the biophysical changes between the two models are presented in Fig. 11 and Fig. S10. From Fig. 11 one can clearly see that the magnitude of $\partial T_{s} / \partial \alpha$ and $\partial T_{s} / \partial G$ in the CESM model is slightly larger than that in the GFDL-ESM2Mb model, while the magnitude of $\partial T_{s} / \partial r_{a}$ and $\partial T_{s} / \partial r_{s}$ is similar between the two models. In terms of the magnitude of the biophysical changes, the changes in albedo, aerodynamic resistance, and heat storage in the GFDL-ESM2Mb model are generally smaller than their counterparts in the CESM model; however, there 

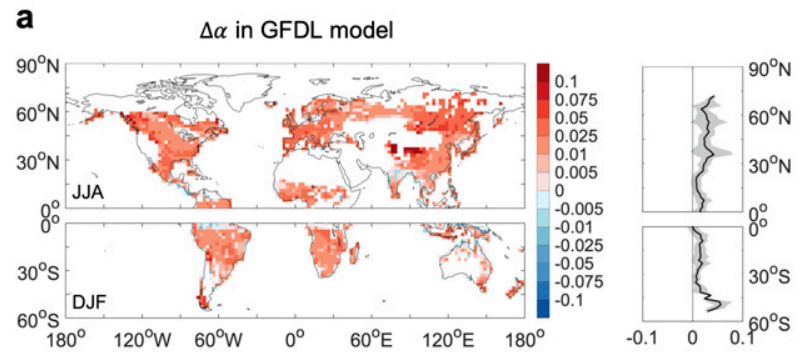

C
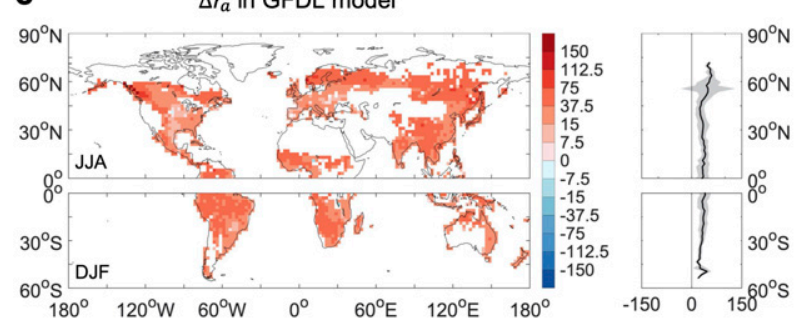

e

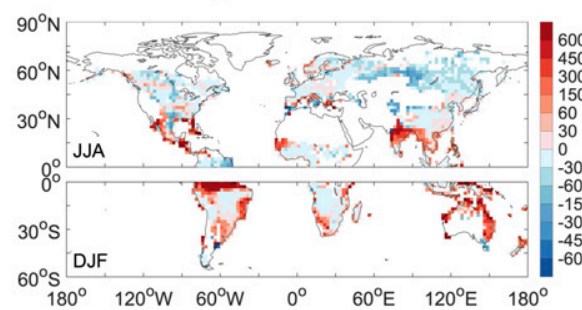

g
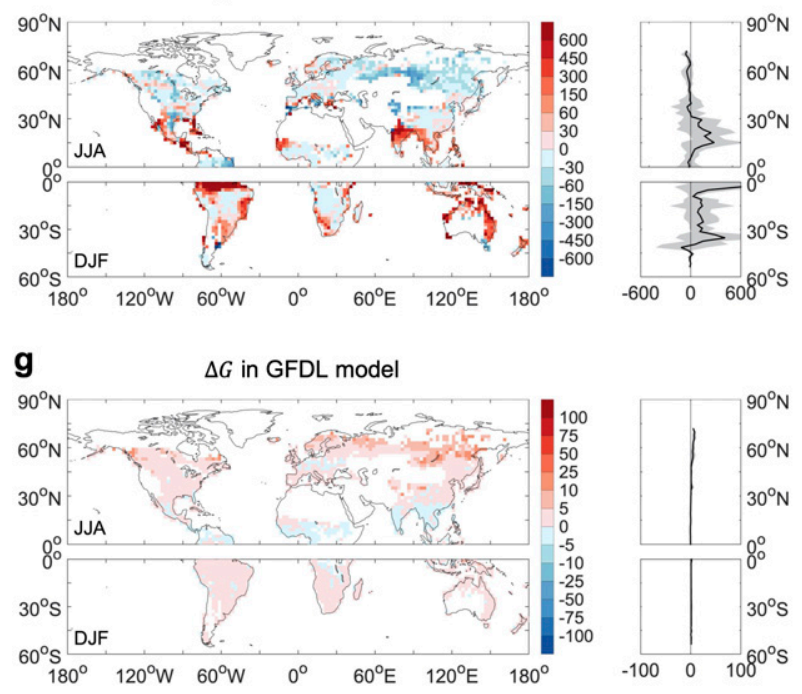

b

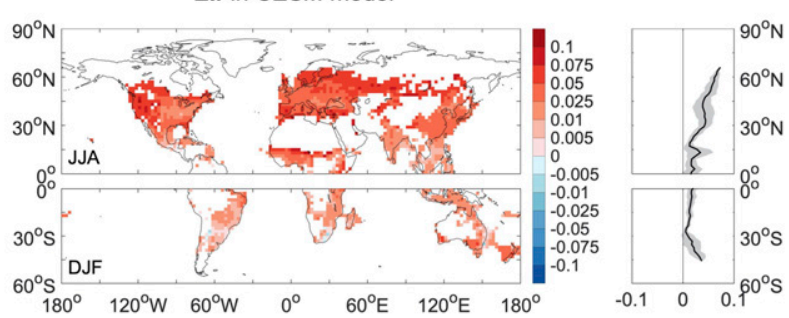

d

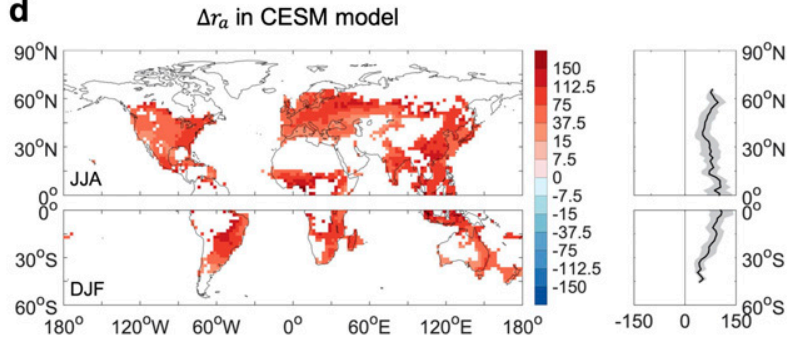

f
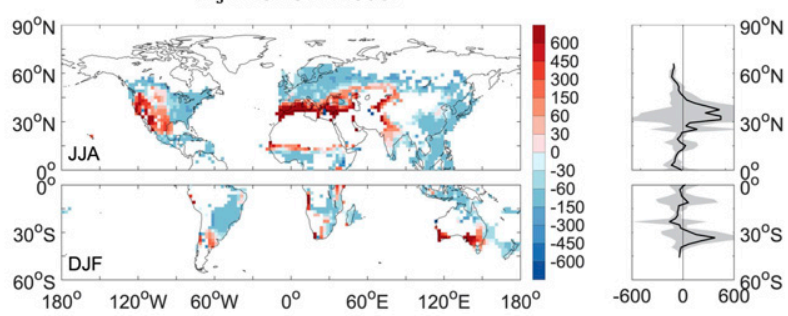

h

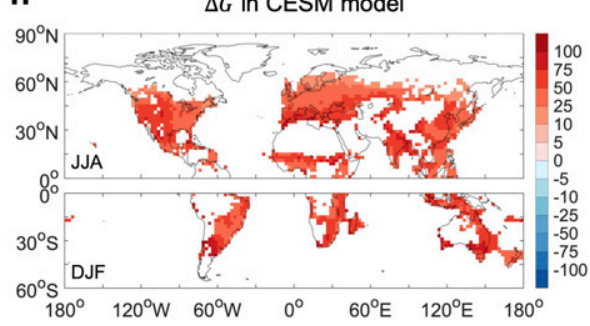

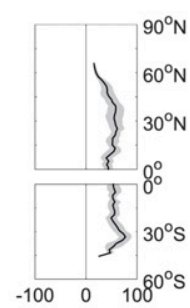

FIG. 10. A comparison of the changes $(\Delta=$ cropland - forest $)$ of albedo $\left(\Delta \alpha\right.$, nondimensional), aerodynamic resistance $\left(\Delta r_{a}, \mathrm{~s} \mathrm{~m}^{-1}\right)$, surface resistance $\left(\Delta r_{s}, \mathrm{~s} \mathrm{~m}^{-1}\right)$, and heat storage $\left(\Delta G, \mathrm{~W} \mathrm{~m}^{-2}\right)$ in (left) the GFDL-ESM2Mb and (right) the CESM models during summer.

seems to be no consistency between the two models in terms of the differences in surface resistance changes, which show very large spatial variations.

Figure 12 and Fig. S11 further present the fractional differences $(\tilde{\delta})$ in terms of the sensitivities and the biophysical changes between the two models and Fig. 13 and Fig. S12 summarize the global picture of the fractional differences. It can be seen that relatively speaking the fractional differences in terms of the sensitivities are smaller than those of the corresponding changes (Fig. 13 and Fig. S12). The median values of the fractional differences are about $20 \%-50 \%$ for the sensitivities but about $55 \%-100 \%$ for the biophysical changes in summer.
In winter, the median values of the fractional differences are about $30 \%-75 \%$ for the sensitivities but about $85 \%-$ $140 \%$ for the biophysical changes. This suggests that the dissimilarity between the two models is more related to the magnitude of biophysical changes (e.g., $\Delta \alpha, \Delta r_{a}, \Delta r_{s}$, and $\Delta G)$ than the sensitivities. Nevertheless, there are still important differences between the two models in terms of the sensitivities ( $\sim 20 \%-50 \%$ in summer and $\sim 30 \%-75 \%$ in winter).

It is perhaps not too surprising to see that the two models exhibit stronger dissimilarity in the biophysical changes than the sensitivities because the biophysical changes are directly related to the model structure and 
a

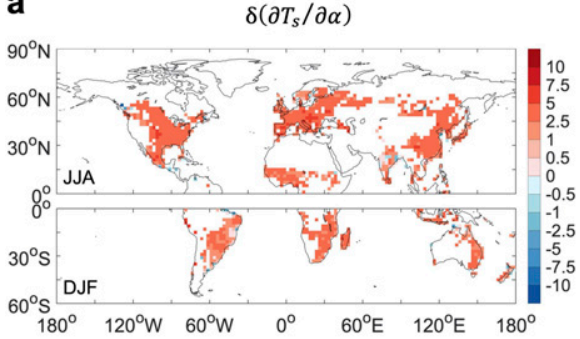

C

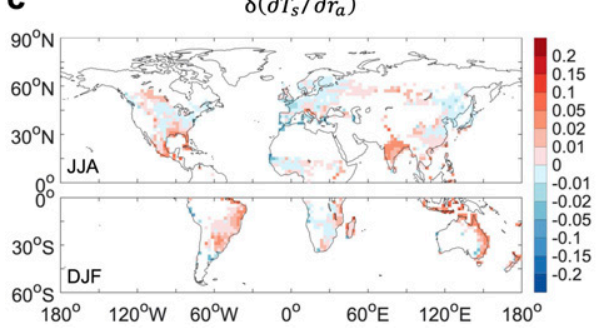

e $\delta\left(\partial T_{s} / \partial r_{s}\right)$

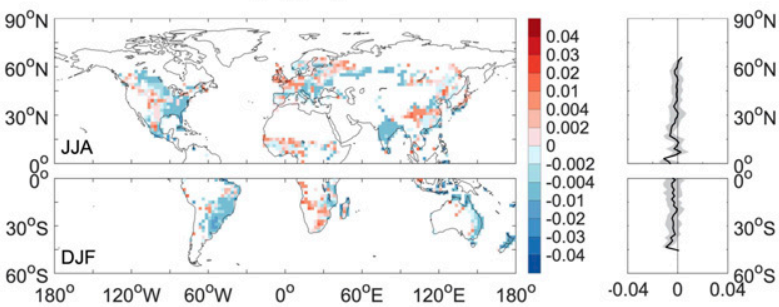

g $\delta\left(\partial T_{s} / \partial G\right)$
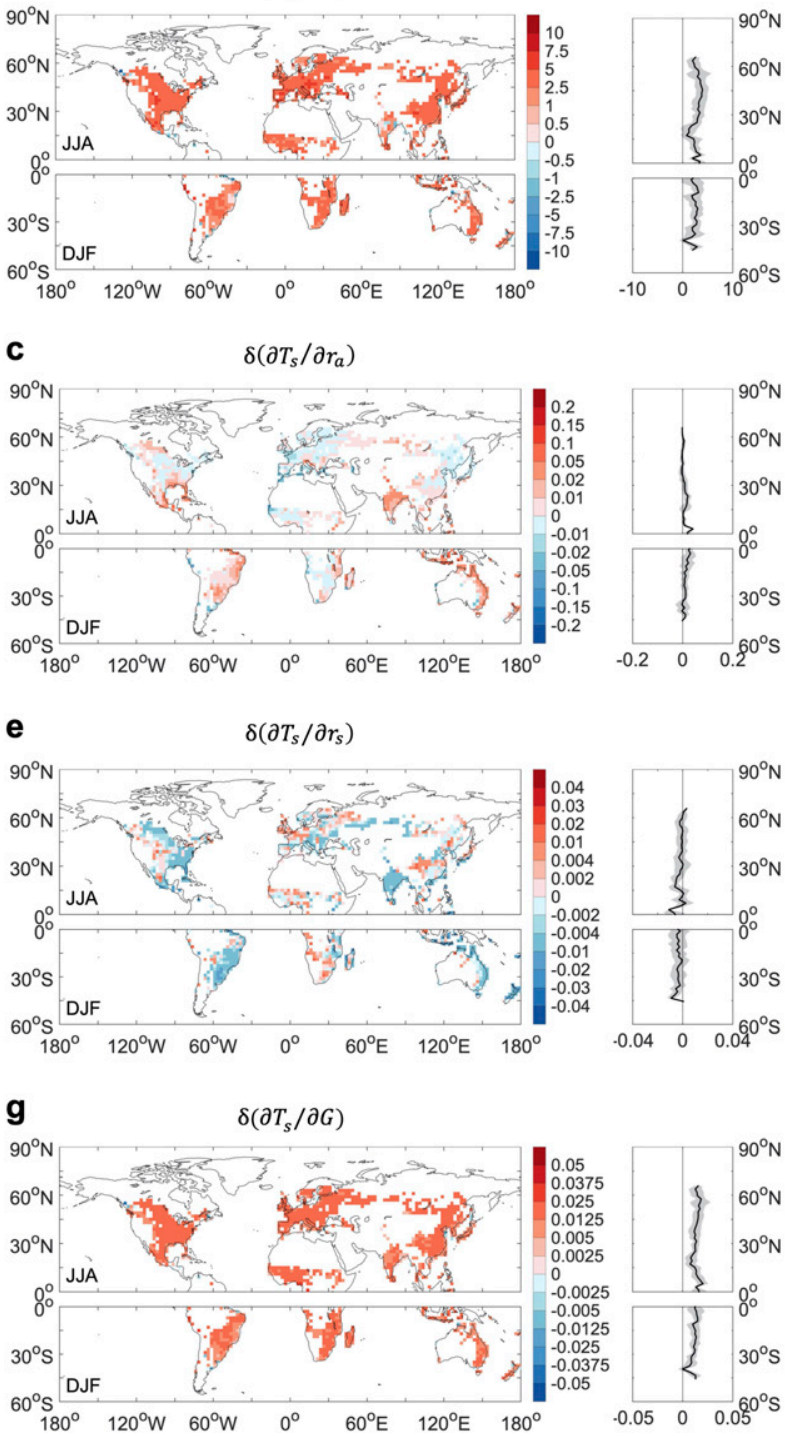

b
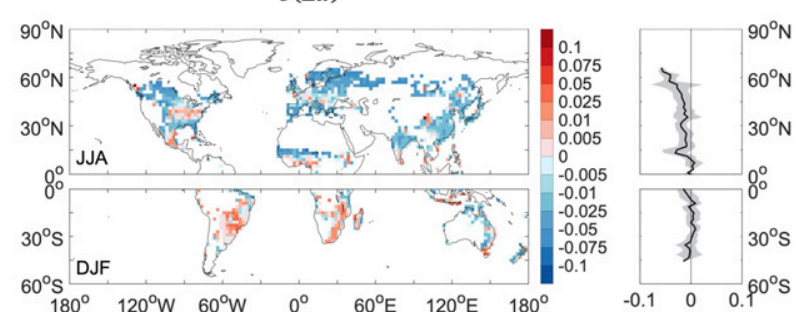

d
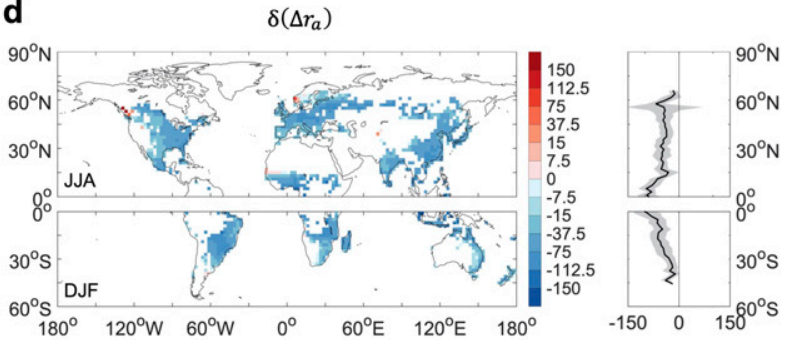

f
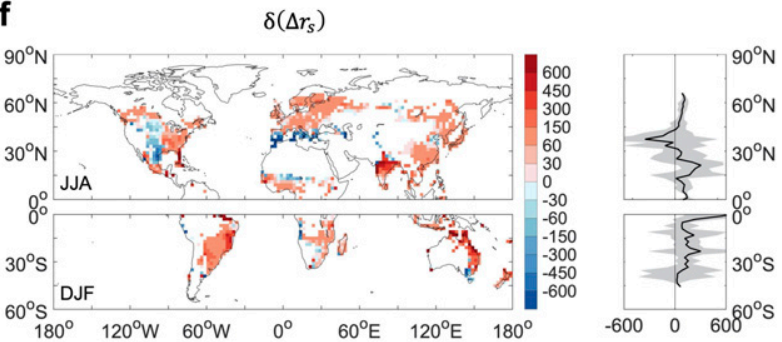

h

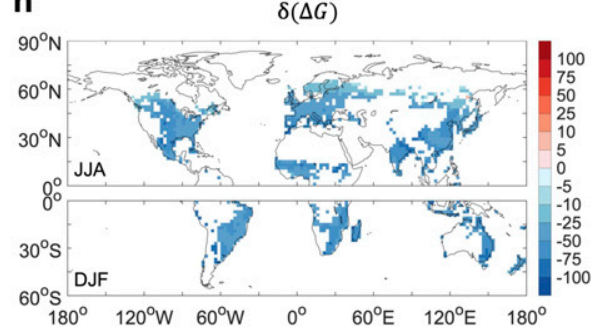

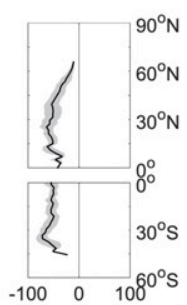

FIG. 11. The differences $(\delta)$ in terms of (left) the sensitivities and (right) the biophysical changes between the GFDL-ESM2Mb and the CESM models (GFDL minus CESM) during summer.

parameterization differences (e.g., how the models represent forests and parameterize the biophysical processes associated with forest-atmosphere interactions) but the sensitivities are constrained by the surface energy balance equation (i.e., the surface energy balance equation decides how the surface temperature should respond to biophysical perturbations). In particular, we highlight that the sensitivity of LST to aerodynamic resistance shows the smallest difference between the two models compared to the other sensitivities. The median fractional difference for the sensitivity of LST to aerodynamic resistance is only about $19.1 \%$ in summer and $32.8 \%$ in winter. A possible cause is the feedback between the sensible heat flux, latent heat flux, and outgoing longwave radiation when some perturbation is introduced. In our study, the surface energy balance equation is essentially written as

$$
S_{\text {in }}(1-\alpha)+\varepsilon L_{\text {in }}-G=H+L E+\varepsilon \sigma T_{s}^{4},
$$

where the lhs is treated not as a function of surface temperature, but the rhs is treated as a function of surface temperature. According to the above surface energy balance equation, when $\alpha$ or $G$ is reduced, all three terms on the rhs $(H, L E$, and the outgoing longwave radiation) will be directly impacted and increased (see solid lines in Fig. 14a). Since the outgoing longwave 
a

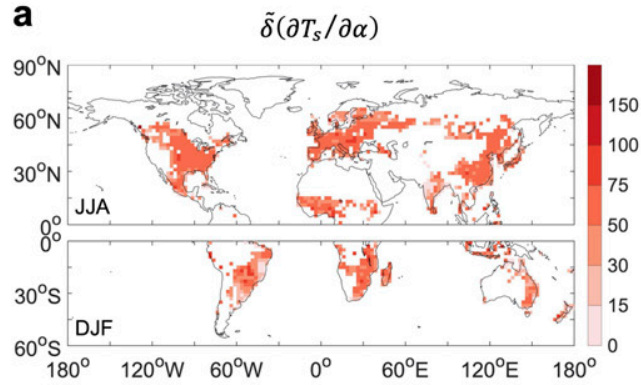

C $\quad \tilde{\delta}\left(\partial T_{s} / \partial r_{a}\right)$

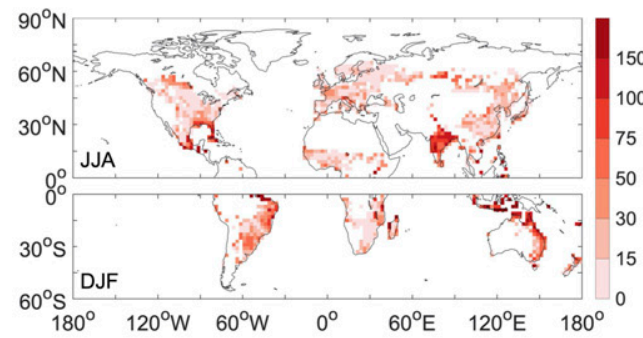

e $\quad \tilde{\delta}\left(\partial T_{s} / \partial r_{s}\right)$

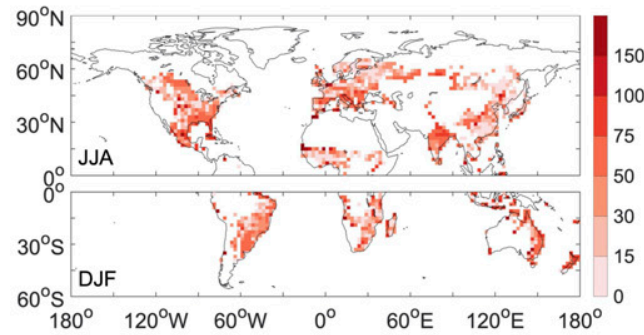

g

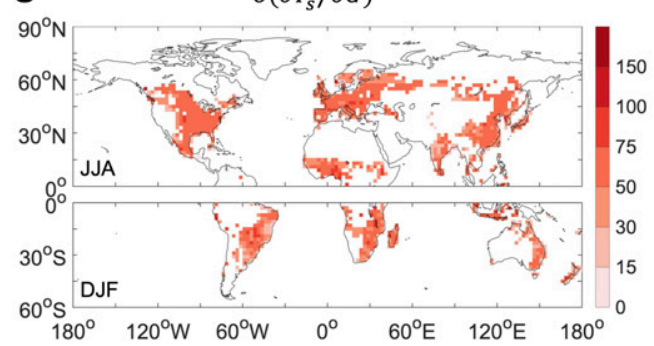

b

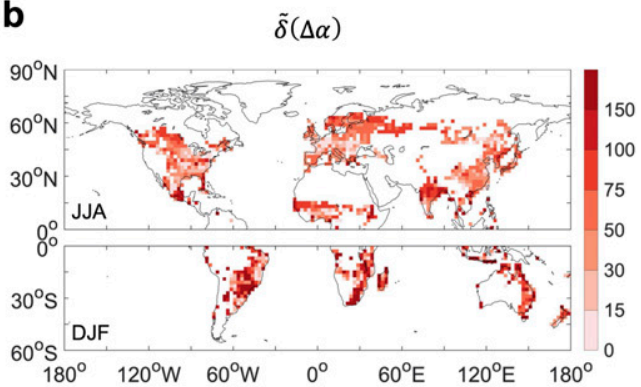

d

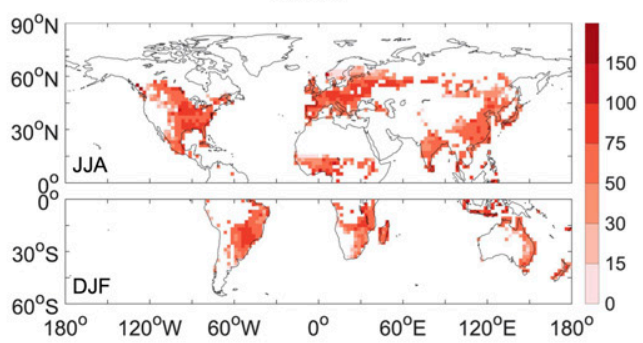

f

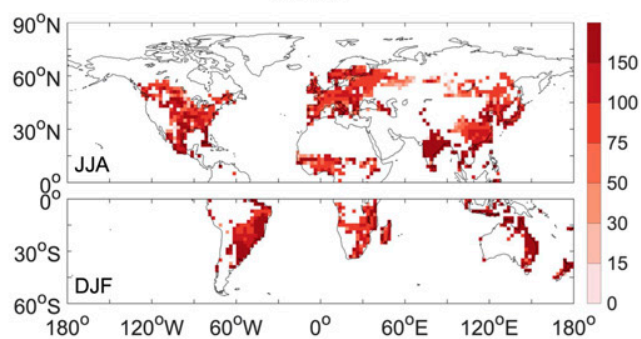

h

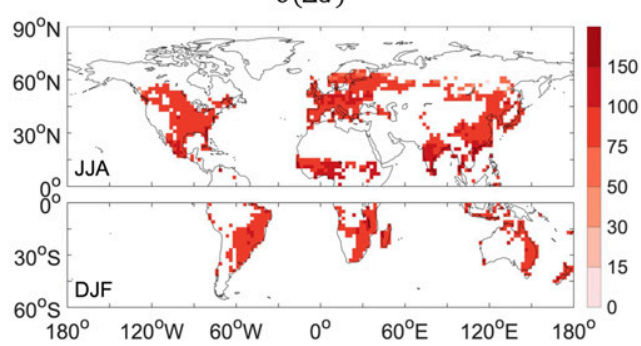

FIG. 12. The fractional differences $(\tilde{\delta})$ in terms of (left) the sensitivities and (right) the biophysical changes between the GFDL-ESM2Mb and the CESM models during summer. Units are $\%$.

radiation is essentially only a function of LST (we have assumed that emissivity is constant), the LST will be also increased. This will cause positive feedbacks because as LST increases, $H$ and $L E$ will further increase (see dashed lines in Fig. 14a).

When $r_{a}$ is increased, the direct impact is that $H$ and $L E$ will be reduced (solid lines in Fig. 14b). However, there are important negative feedbacks that need to be considered (dashed lines in Fig. 14b): to balance the reductions of $H$ and $L E$, the outgoing longwave radiation and the LST will have to increase; when the LST increases, it will further cause the $H$ and $L E$ to increase, thereby creating negative feedbacks (compared to the direct impacts). Such negative feedbacks cause $\partial T_{s} / \partial r_{a}$ to be more robust across models.

Similarly, negative feedbacks can occur when $r_{s}$ is increased. The direct effect of increasing $r_{s}$ is a decrease of $L E$ (solid lines in Fig. 14c), which further leads to an 


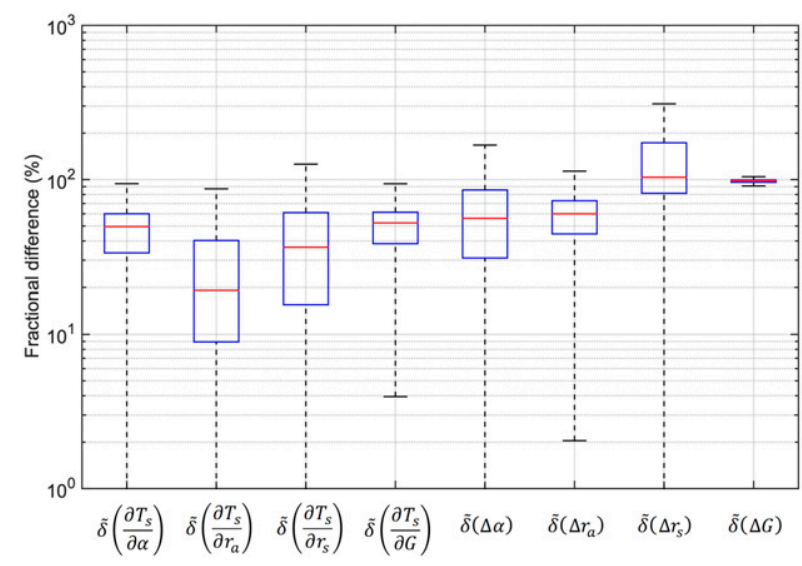

FIG. 13. Boxplots of the fractional differences $(\tilde{\delta})$ in terms of the sensitivities and the biophysical changes during summer.

increase in the outgoing longwave radiation and the LST (as well as sensible heat flux). This increase in the LST in return causes the $L E$ to increase (dashed lines in Fig. 14c). This negative feedback associated with changing $r_{s}$ might explain that even though the two models have very different $\Delta r_{s}$, the sensitivity $\partial T_{s} / \partial r_{s}$ is actually similar (or at least much less different than $\Delta r_{s}$ ). One key difference between $r_{a}$ and $r_{s}$ is that when $r_{a}$ increases both $H$ and $L E$ experience direct impacts and negative feedbacks, but increasing $r_{s}$ causes $L E$ to experience direct impacts and negative feedbacks and causes $H$ to experience direct impacts and positive feedbacks. This might explain why $\partial T_{s} / \partial r_{a}$ shows even smaller differences than $\partial T_{s} / \partial r_{s}$ (and also the other sensitivities) between the two models.

Last, we stress that the robustness of $\partial T_{s} / \partial r_{a}$ between the two models does not contradict the finding that aerodynamic resistance is the most important biophysical factor that controls the surface temperature response to deforestation. The robustness of $\partial T_{s} / \partial r_{a}$ does not imply that $\partial T_{s} / \partial r_{a}$ is small; rather, it implies that $\partial T_{s} / \partial r_{a}$ is strongly constrained by the surface energy balance equation. On the other hand, the aerodynamic resistance contribution to the surface temperature response to deforestation is the product of the sensitivity $\left(\partial T_{s} / \partial r_{a}\right)$ and the change in aerodynamic resistance $\left(\Delta r_{a}\right)$, both of which are fairly large when comparing forests to croplands (see Figs. 9 and 10). It is the contribution that determines which factor most strongly controls the surface temperature response to deforestation in our attribution framework.

\section{Conclusions}

Subgrid-scale information from land surface models is a powerful tool for investigating the impacts of LULCC on the local surface climate (Schultz et al. 2016; Malyshev et al. 2015). Taking advantage of subgrid-scale outputs from two global ESMs and using an improved attribution framework, we study the LST response to deforestation through biophysical pathways. The results show that in summer the subgrid LST contrast between croplands and forests (i.e., croplands minus forests) is positive over the globe and reaches its maximum in the midlatitudes in the GFDL-ESM2Mb simulation, but negative near the northern high latitudes and over eastern America, India, and eastern China in the CESM simulation; in winter, the subgrid LST contrast between croplands and forests is overall positive in the tropics and negative in the high latitudes in the two model simulations. By attributing the LST change to contributions from changes in different biophysical factors, we find that the warming effect induced by changes in aerodynamic resistance can be dampened by the cooling a

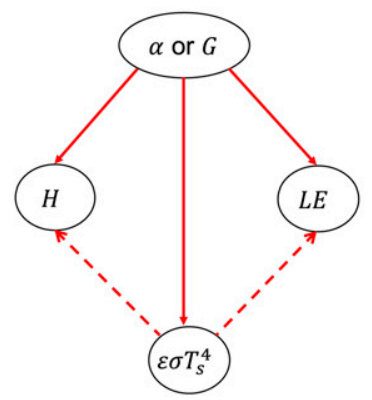

b

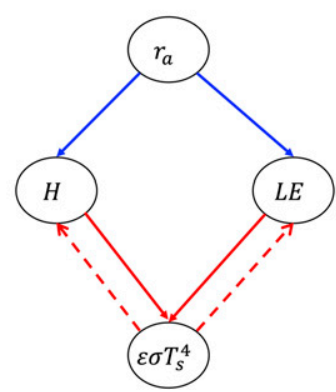

C

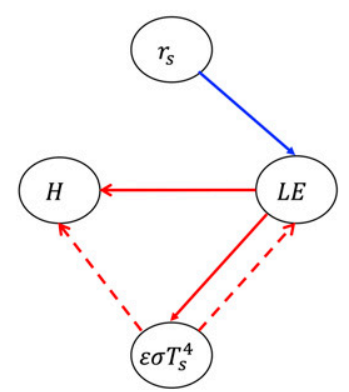

FIG. 14. Feedbacks associated with LST changes caused by (a) reducing albedo or heat storage, (b) increasing aerodynamic resistance, and (c) increasing surface resistance. Arrows with solid lines are direct effects before LST changes (i.e., outgoing longwave radiation has not changed) and arrows with dashed lines are indirect effects after LST changes (i.e., outgoing longwave radiation has changed). The red arrows are positive effects and the blue arrows are negative effects. 
effects induced by changes in albedo and surface resistance to some extent. Nevertheless, aerodynamic resistance is the key controlling factor for the LST changes in both summer and winter.

Comparison between the two models shows that the magnitudes of the contributions of aerodynamic resistance, surface resistance and heat storage to LST change in the GFDL-ESM2Mb model are smaller than those in the CESM model. To further investigate the differences in LST responses to deforestation in the two models, the sensitivities of LST to albedo, aerodynamic resistance, surface resistance, and heat storage, and the corresponding biophysical changes are compared. The results show that the sensitivities of LST to albedo and heat storage are consistently negative while the sensitivities of LST to aerodynamic resistance and surface resistance are overall positive. The differences between the two models in terms of the sensitivities are smaller than those of the corresponding changes, indicating that the dissimilarity between the two models in terms of LST responses to deforestation is more related to the magnitude of biophysical changes. Furthermore, caused by the feedbacks between the sensible heat flux, latent heat flux, and outgoing longwave radiation, the sensitivity of LST to aerodynamic resistance shows the smallest difference between the two models compared to the other sensitivities.

Again, we should note that the GFDL-ESM2Mb and CESM models have very different strategies to represent subgrid land surface heterogeneity and different biophysical parameterizations. In addition, from the land's perspective, the two models have different atmospheric forcing conditions (e.g., incoming shortwave and longwave radiation), as shown in previous studies (Wild et al. 2015). All of these differences can lead to differences in terms of the diagnosed effects of deforestation. In addition, the differences between the two models presented in this study can also be caused by the different types of trees aggregated for forests and different types of crops aggregated for croplands. Nevertheless, it is the first time that the subgrid-scale LST variability is comprehensively studied with two widely used global ESMs. The comparison yields new insights into the similarity and dissimilarity in terms of how the biophysical processes are represented in different ESMs. Furthermore, taking advantages of the subgrid outputs from the ongoing LUMIP in CMIP6 in the near future, the attribution framework developed in the study will be a useful tool to improve our understanding of the LULCC impacts on the local surface climate.

Acknowledgments. We thank Dr. Sergey Malyshev at GFDL for providing the GFDL simulations used in this study. This work was supported by the National Key Research and Development Program of China (Grant 2019YFA0607203 and 2017YFA0604404), the National Natural Science Foundation of China (Grant 41901327), the Guangdong Basic and Applied Basic Research Foundation (Grant 2019A1515010823), the Fundamental Research Funds for the Central Universities (Grant 19lgpy41), the project funded by China Postdoctoral Science Foundation (Grant 2020M672937 and 2020T130732), and the NSF Established Program to Stimulate Competitive Research (1101245 and 1832959). We would also like to recognize the computational support provided by the NCAR Computational and Information Systems Laboratory for computing, processing, and data storage of CESM model data.

\section{REFERENCES}

Arora, V. K., and G. J. Boer, 2010: Uncertainties in the 20th century carbon budget associated with land use change. Global Change Biol., 16, 3327-3348, https://doi.org/10.1111/j.13652486.2010.02202.x.

Bonan, G. B., 2008: Forests and climate change: Forcings, feedbacks, and the climate benefits of forests. Science, 320, 1444 1449, https://doi.org/10.1126/science.1155121.

_ 2016: Forests, climate, and public policy: A 500-year interdisciplinary odyssey. Annu. Rev. Ecol. Evol. Syst., 47, 97-121, https://doi.org/10.1146/annurev-ecolsys-121415-032359.

Boysen, L. R., V. Brovkin, V. K. Arora, P. Cadule, N. de NobletDucoudré, E. Kato, J. Pongratz, and V. Gayler, 2014: Global and regional effects of land-use change on climate in 21st century simulations with interactive carbon cycle. Earth Syst. Dyn., 5, 309-319, https://doi.org/10.5194/esd-5-309-2014.

Bright, R. M., K. Zhao, R. B. Jackson, and F. Cherubini, 2015: Quantifying surface albedo and other direct biogeophysical climate forcings of forestry activities. Global Change Biol., 21, 3246-3266, https://doi.org/10.1111/gcb.12951.

Brovkin, V., S. Sitch, W. Von Bloh, M. Claussen, E. Bauer, and W. Cramer, 2004: Role of land cover changes for atmospheric $\mathrm{CO}_{2}$ increase and climate change during the last 150 years. Global Change Biol., 10, 1253-1266, https://doi.org/10.1111/ j.1365-2486.2004.00812.x.

Burakowski, E., A. Tawfik, A. Ouimette, L. Lepine, K. Novick, S. Ollinger, C. Zarzycki, and G. Bonan, 2018: The role of surface roughness, albedo, and Bowen ratio on ecosystem energy balance in the eastern United States. Agric. For. Meteor., 249, 367376, https://doi.org/10.1016/j.agrformet.2017.11.030.

Chen, L., and P. A. Dirmeyer, 2016: Adapting observationally based metrics of biogeophysical feedbacks from land cover/land use change to climate modeling. Environ. Res. Lett., 11, 034002 034014, https://doi.org/10.1088/1748-9326/11/3/034002.

$\longrightarrow$, and - 2020: Reconciling the disagreement between observed and simulated temperature responses to deforestation. Nat. Commun., 11, 202, https://doi.org/10.1038/s41467-019-14017-0.

Davin, E. L., and N. de Noblet-Ducoudré, 2010: Climatic impact of global-scale deforestation: Radiative versus nonradiative processes. J. Climate, 23, 97-112, https://doi.org/10.1175/ 2009JCLI3102.1.

de Noblet-Ducoudré, N., and Coauthors, 2012: Determining robust impacts of land-use-induced land cover changes on surface 
climate over North America and Eurasia: Results from the first set of LUCID experiments. J. Climate, 25, 3261-3281, https://doi.org/10.1175/JCLI-D-11-00338.1.

Dunne, J. P., and Coauthors, 2012: GFDL's ESM2 global coupled climate-carbon Earth System Models. Part I: Physical formulation and baseline simulation characteristics. J. Climate, 25, 6646-6665, https://doi.org/10.1175/JCLI-D-11-00560.1. , and Coauthors, 2013: GFDL's ESM2 global coupled climatecarbon Earth System Models. Part II: Carbon system formulation and baseline simulation characteristics. J. Climate, 26, 2247-2267, https://doi.org/10.1175/JCLI-D-12-00150.1.

Feddema, J. J., K. W. Oleson, G. B. Bonan, L. O. Mearns, L. E. Buja, G. A. Meehl, and W. M. Washington, 2005: The importance of land-cover change in simulating future climates. Science, $\mathbf{3 1 0}$, 1674-1678, https://doi.org/10.1126/science.1118160.

Findell, K. L., E. Shevliakova, P. C. D. Milly, and R. J. Stouffer, 2007: Modeled impact of anthropogenic land cover change on climate. J. Climate, 20, 3621-3634, https://doi.org/10.1175/JCLI4185.1.

Hurtt, G. C., and Coauthors, 2011: Harmonization of land-use scenarios for the period 1500-2100: 600 years of global gridded annual land-use transitions, wood harvest, and resulting secondary lands. Climatic Change, 109, 117-161, https://doi.org/ 10.1007/s10584-011-0153-2.

Lawrence, D. M., and Coauthors, 2016: The Land Use Model Intercomparison Project (LUMIP) contribution to CMIP6: Rationale and experimental design. Geosci. Model Dev., 9, 2973-2998, https://doi.org/10.5194/gmd-9-2973-2016.

Lawrence, P. J., and T. N. Chase, 2010: Investigating the climate impacts of global land cover change in the community climate system model. Int. J. Climatol., 30, 2066-2087, https://doi.org/ 10.1002/joc. 2061.

Lee, X., and Coauthors, 2011: Observed increase in local cooling effect of deforestation at higher latitudes. Nature, 479, 384387, https://doi.org/10.1038/nature10588.

Li, D., W. Liao, A. J. Rigden, X. Liu, D. Wang, S. Malyshev, and E. Shevliakova, 2019: Urban heat island: Aerodynamics or imperviousness? Sci. Adv., 5, eaau4299, https://doi.org/10.1126/ sciadv.aau4299.

Li, Y., M. Zhao, S. Motesharrei, Q. Mu, E. Kalnay, and S. Li, 2015 Local cooling and warming effects of forests based on satellite observations. Nat. Commun., 6, 6603, https://doi.org/10.1038/ ncomms7603.

_, N. de Noblet-Ducoudré, E. L. Davin, S. Motesharrei, N. Zeng, $\mathrm{S}$. Li, and E. Kalnay, 2016: The role of spatial scale and background climate in the latitudinal temperature response to deforestation. Earth Syst. Dyn., 7, 167-181, https://doi.org/10.5194/esd-7-167-2016.

Liao, W., A. J. Rigden, and D. Li, 2018: Attribution of local temperature response to deforestation. J. Geophys. Res. Biogeosci., 123, 1572-1587, https://doi.org/10.1029/2018JG004401.

Luyssaert, S., and Coauthors, 2014: Land management and landcover change have impacts of similar magnitude on surface temperature. Nat. Climate Change, 4, 389-393, https://doi.org/ 10.1038/nclimate2196.

Mahmood, R., and Coauthors, 2014: Land cover changes and their biogeophysical effects on climate. Int. J. Climatol., 34, 929953, https://doi.org/10.1002/joc.3736.

Malyshev, S., E. Shevliakova, R. J. Stouffer, and S. W. Pacala, 2015: Contrasting local versus regional effects of land-use-changeinduced heterogeneity on historical climate: Analysis with the GFDL Earth System Model. J. Climate, 28, 5448-5469, https:// doi.org/10.1175/JCLI-D-14-00586.1.

Milly, P. C. D., and Coauthors, 2014: An enhanced model of land water and energy for global hydrologic and earth-system studies. J. Hydrometeor., 15, 1739-1761, https://doi.org/10.1175/ JHM-D-13-0162.1.

Monteith, J., and M. Unsworth, 2013: Principles of Environmental Physics. 4th ed. Academic Press, 440 pp.

Moon, M., D. Li, W. Liao, A. J. Rigden, and M. A. Friedl, 2020: Modification of surface energy balance during springtime: The relative importance of biophysical and meteorological changes. Agric. For. Meteor., 284, 107905, https://doi.org/ 10.1016/j.agrformet.2020.107905.

Neale, R. B., and Coauthors, 2010: Description of the NCAR Community Atmosphere Model (CAM 5.0). NCAR Tech. Note NCAR/TN-486+STR, 268 pp., http://www.cesm.ucar.edu/ models/cesm1.1/cam/docs/description/cam5_desc.pdf.

Oleson, K. W., and Coauthors, 2013: Technical Description of version 4.5 of the Community Land Model (CLM). NCAR Tech. Note NCAR/TN-503+STR, 420 pp., https://doi.org/ 10.5065/D6RR1W7M

Pielke, R. A., and Coauthors, 2011: Land use/land cover changes and climate: Modeling analysis and observational evidence. Wiley Interdiscip. Rev.: Climate Change, 2, 828-850, https:// doi.org/10.1002/wcc.144.

Pitman, A. J., and Coauthors, 2009: Uncertainties in climate responses to past land cover change: First results from the LUCID intercomparison study. Geophys. Res. Lett., 36, L14814, https://doi.org/10.1029/2009GL039076.

Qu, X., and A. Hall, 2013: On the persistent spread in snow-albedo feedback. Climate Dyn., 42, 69-81, https://doi.org/10.1007/ s00382-013-1774-0.

Rigden, A. J., and D. Li, 2017: Attribution of surface temperature anomalies induced by land use and land cover changes. Geophys. Res. Lett., 44, 6814-6822, https://doi.org/10.1002/2017GL073811.

Rotenberg, E., and D. Yakir, 2011: Distinct patterns of changes in surface energy budget associated with forestation in the semiarid region. Global Change Biol., 17, 1536-1548, https:// doi.org/10.1111/j.1365-2486.2010.02320.x.

Schultz, N. M., X. Lee, P. J. Lawrence, D. M. Lawrence, and L. Zhao, 2016: Assessing the use of subgrid land model output to study impacts of land cover change. J. Geophys. Res. Atmos., 121, 6133-6147, https://doi.org/10.1002/2016jd025094. P. J. Lawrence, and X. Lee, 2017: Global satellite data highlights the diurnal asymmetry of the surface temperature response to deforestation. J. Geophys. Res. Biogeosci., 122, 903-917, https://doi.org/10.1002/2016JG003653.

Shevliakova, E., and Coauthors, 2009: Carbon cycling under 300 years of land use change: Importance of the secondary vegetation sink. Global Biogeochem. Cycles, 23, GB2022, https:// doi.org/10.1029/2007gb003176.

, R. J. Stouffer, S. Malyshev, J. P. Krasting, G. C. Hurtt, and S. W. Pacala, 2013: Historical warming reduced due to enhanced land carbon uptake. Proc. Natl. Acad. Sci. USA, 110, 16 730-16735, https://doi.org/10.1073/pnas.1314047110.

Wang, P., D. Li, W. Liao, A. Rigden, and W. Wang, 2019: Contrasting evaporative responses of ecosystems to heatwaves traced to the opposing roles of vapor pressure deficit and surface resistance. Water Resour. Res., 55, 4550-4563, https:// doi.org/10.1029/2019WR024771.

Wild, M., and Coauthors, 2015: The energy balance over land and oceans: An assessment based on direct observations and CMIP5 climate models. Climate Dyn., 44, 3393-3429, https:// doi.org/10.1007/s00382-014-2430-z.

Zeng, Z., and Coauthors, 2017: Climate mitigation from vegetation biophysical feedbacks during the past three decades. Nat. Climate Change, 7, 432-436, https://doi.org/10.1038/nclimate3299. 